Article

\title{
Proteomic Characterization of Two Medically Important Malaysian Snake Venoms, Calloselasma rhodostoma (Malayan Pit Viper) and Ophiophagus hannah (King Cobra)
}

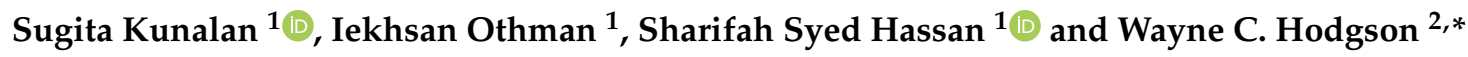 \\ 1 Jeffrey Cheah School of Medicine and Health Sciences, Monash University Malaysia, Jalan Lagoon Selatan, \\ Bandar Sunway, Selangor Darul Ehsan 47500, Malaysia; sugitakunalan@hotmail.com (S.K.); \\ iekhsan.othman@monash.edu (I.O.); sharifah.syedhassan@monash.edu (S.S.H.) \\ 2 Monash Venom Group, Department of Pharmacology, Faculty of Medicine, Nursing and Health Sciences, \\ Monash University, Victoria 3800, Australia \\ * Correspondence: wayne.hodgson@monash.edu; Tel.: +61-399-054-861
}

Received: 18 October 2018; Accepted: 23 October 2018; Published: 26 October 2018

\begin{abstract}
Calloselasma rhodostoma (CR) and Ophiophagus hannah $(\mathrm{OH})$ are two medically important snakes found in Malaysia. While some studies have described the biological properties of these venoms, feeding and environmental conditions also influence the concentration and distribution of snake venom toxins, resulting in variations in venom composition. Therefore, a combined proteomic approach using shotgun and gel filtration chromatography, analyzed by tandem mass spectrometry, was used to examine the composition of venoms from these Malaysian snakes. The analysis revealed 114 proteins (15 toxin families) and 176 proteins (20 toxin families) in Malaysian Calloselasma rhodostoma and Ophiophagus hannah species, respectively. Flavin monoamine oxidase, phospholipase $\mathrm{A}_{2}$, phosphodiesterase, snake venom metalloproteinase, and serine protease toxin families were identified in both venoms. Aminopeptidase, glutaminyl-peptide cyclotransferase along with ankyrin repeats were identified for the first time in CR venom, and insulin, c-type lectins/snaclecs, hepatocyte growth factor, and macrophage colony-stimulating factor together with tumor necrosis factor were identified in $\mathrm{OH}$ venom for the first time. Our combined proteomic approach has identified a comprehensive arsenal of toxins in $\mathrm{CR}$ and $\mathrm{OH}$ venoms. These data may be utilized for improved antivenom production, understanding pathological effects of envenoming, and the discovery of biologically active peptides with medical and/or biotechnological value.
\end{abstract}

Keywords: Calloselasma rhodostoma; Ophiophagus hannah; toxin; proteomics; venomics; venom proteome

Key Contribution: Though earlier investigations have provided insight into the major families of toxins in these Malaysian venoms, our work has identified several yet undiscovered proteins: Aminopeptidase; glutaminyl-peptide cyclotransferase and ankyrin repeats in CR venom as well as insulin; and c-type lectins along with several notable growth factors in $\mathrm{OH}$ venom.

\section{Introduction}

Approximately 5.5 million people are victims of snake bites every year, causing about 400,000 amputations, and 20,000 to 125,000 fatalities [1], representing a global public health burden. Despite its destructive propensity, snake venom has been studied to identify lead compounds for use as therapeutic agents. Promising reports of antimicrobial (bacteria, virus, fungi, and protozoa), anti-inflammatory, antinociceptive, anti-cancer, anti-hypertensive, anti-coagulation, 
and anti-fibrinolytic activities of snake venoms [2-7] have initiated more intensive investigations of venom and venom glands using venomics [8,9]. However, it is widely hypothesized that feeding and environmental conditions influence the concentration and distribution of snake venom components, causing variation between individual, species, genus, and families [10]. Such variation can have major medical implications for the treatment of human snakebite victims. Thus, the reason for the conception of venomics and optimism is that characterization of the large protein variability within snake venoms may contribute to a deeper understanding of their biological as well as pathological effects.

In this study, we investigated the proteomic composition of Calloselasma rhodostoma and Ophiohagus hannah venoms, two medically important snakes found in Malaysia [11]. Both venoms are a rich source of proteins that have been reported to contain biologically active peptides with medical and biotechnological value. One such example is Ancrod (or Viprinex ${ }^{\circledR}$ ), a snake venom serine protease purified from C. rhodostoma venom. Ancrod is a thrombin-like enzyme that breaks down fibrinogen and was developed for the treatment of ischaemic stroke and myocardial infarction as well as deep-vein thrombosis [12,13]. However, Ancrod has been suspended from use due to inconclusive clinical trial results $[14,15]$. Another example is the $\alpha$-neurotoxin, hannalgesin, that was derived from a small peptide called prohanin, originating from the venom of $O$. hannah [16]. Despite being an $\alpha$-neurotoxin, hannalgesin does not paralyze skeletal muscles, but provides analgesic effects. However, the development of the drug was terminated in the preclinical phase $[17,18]$.

Until recently, there have been relatively few reports on the proteomic profile of these two medically important Malaysian snakes. In a comprehensive study by Tang et al., a total of 96 proteins were identified for C. rhodostoma venom [19]. The study employed a series of chromatographic separations, followed by in-gel tryptic digestion of one-dimension (1D) gel electrophoresis proteins and, lastly, identification based on mass spectrometry. In earlier investigations, C. rhodostoma venom proteins were studied using two-dimension (2D) gel electrophoresis together with mass spectrometry. Ali et al. (2013) reported the presence of disintegrin, kallikrein (thrombin-like protein), L-amino acid oxidase (LAAO), lectin, and phospholipase $\mathrm{A}_{2}$ (acidic, basic, and neutral) as well as snake venom metalloproteinases (SVMPs) belonging to six protein families, whereas Vejayan et al., (2014) presented evidence for 26 proteins that could be grouped into six protein families, as demonstrated by Ali et al. [20,21]. Despite the positive identification of toxins, there were 89 unidentified spots that indicates a substantial gap in the complete venom profiling of the C. rhodostoma venom. Apart from the relatively small number of identified proteins, both studies did not provide information on the relative abundance of the identified proteins.

An elaborate venom-gland transcriptomic and venom proteomic study of $O$. hannah venom revealed 128 transcripts and 45 proteins, which were classified into 16 individual protein families [22]. The major protein families reported were three-finger toxin (3FTx), SVMP, cysteine-rich secretory protein (CRiSP), LAAO, Vespryn, phospholipase $\mathrm{A}_{2}\left(\mathrm{PLA}_{2}\right)$, and cobra venom factor (CVF). In addition, nine low abundance $(\leq 2 \%)$ protein families were detected. The results of the study were compared with the Balinese (Indonesian) O. hannah venom investigation by Vonk et al. (2013) [23]. In contrast, they reported 73 proteins using a combination of shotgun and 2D gel electrophoresis. The major protein families described for Balinese $O$. hannah venom were highly similar to the Malaysian O. hannah venom, in which the most abundant toxins were 3FTxs and SVMPs. Although similarities were detected, we know that intraspecies toxin composition variations exist between venoms. As mentioned above, Vejayan et al. (2014) also investigated the proteomic profile of Malaysian O. hannah venom together with $C$. rhodostoma venom. Only 15 proteins belonging to five toxin families could be deduced from 50 spots that were isolated from the 2D gel. The large number of uncharacterized proteins, coupled with the discrepancy of the number of identified proteins between the Malaysian and Indonesian species, indicates the need for further proteomic exploration of Malaysian O. hannah venom.

In this work, we employed a combination of two proteomic approaches to provide a more comprehensive proteomic profile of two medically significant venomous snakes from Malaysia. The first approach involves a direct tryptic digest of freeze-dried crude venom proteins followed by 
ESI-LC-MS/MS, whereas the second approach subjects the crude venom proteins to a molecular-weight based separation prior to tryptic digestion and subsequent ESI-LC-MS/MS. Using this strategy, we report a total of 114 proteins for C. rhodostoma and 176 proteins for O. hannah venoms, successfully identifying more proteins and peptides than previously reported.

\section{Results}

We characterized the venom composition of two Malaysian snakes, i.e., Calloselasma rhodostoma and Ophiophagus hannah, using two proteomic approaches: Direct tryptic digest of freeze-dried crude venom proteins followed by liquid chromatography coupled with electrospray tandem mass spectrometry (shotgun-ESI-LC-MS/MS) and tryptic digest of gel-filtration chromatography venom protein fractions and subsequent liquid chromatography coupled with electrospray tandem mass spectrometry (GF-ESI-LC-MS/MS). The combined approaches revealed a diverse set of data that has been summarized in Tables 1-4 and is discussed in detail below. A complementary visual representation of the crude venom composition is also presented.

\subsection{SDS-PAGE of Crude Venom Proteins}

The overall protein composition of $C$. rhodostoma and $O$. hannah venoms was assessed by 1D SDS-PAGE (Figure 1). The Coomassie Brilliant blue staining showed varying electrophoretic (molecular weight-distribution) protein profiles. This is not surprising as the venom proteins belong to different snake families, one a Viperidae (C. rhodostoma) and the other an Elapidae (O. hannah). The separations revealed that both venoms were composed of highly heterogeneous proteins varying in terms of band intensity as well as migration. Although staining was observed in the entirety of the gel background for both venoms, $O$. hannah venom appears to have more large molecular weight proteins compared to C. rhodostoma venom. C. rhodostoma venom proteins were generally $<60 \mathrm{kDa}$ whereas O. hannah venom proteins appeared to be concentrated in several regions, namely $70 \mathrm{kDa}, 25 \mathrm{kDa}$, and $10 \mathrm{kDa}$.

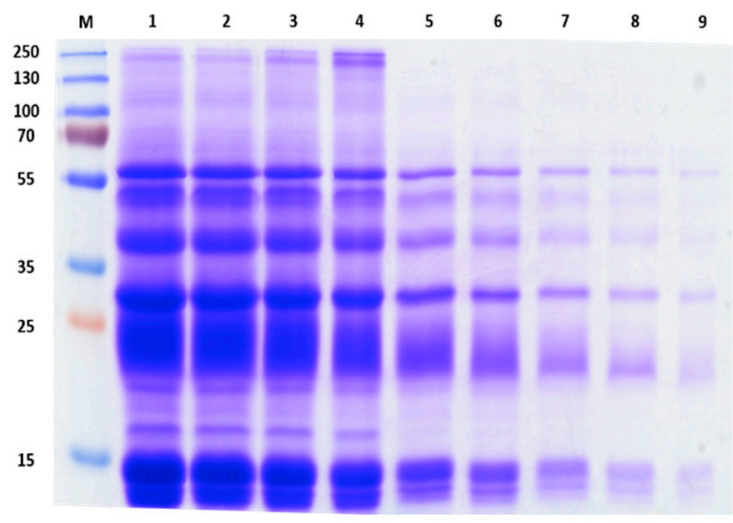

(a)

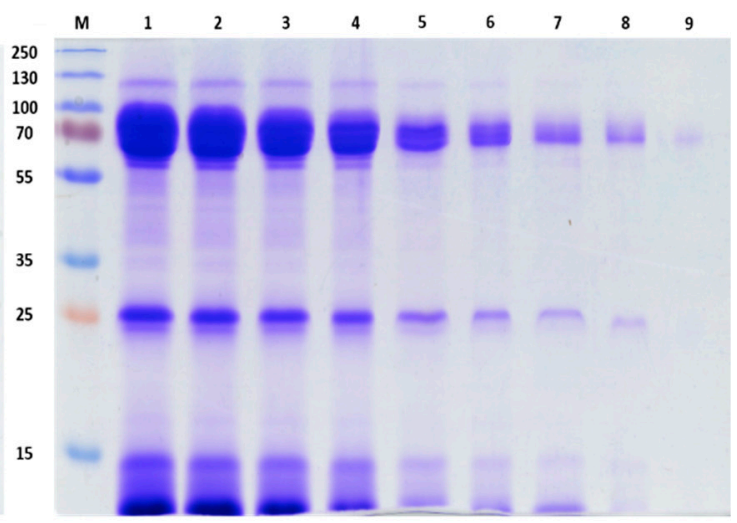

(b)

Figure 1. One-dimension electrophoretic profile of (a) C. rhodostoma and (b) O. hannah venoms. $12 \%$ SDS-PAGE gel picture showing the individual venoms prepared and run in various concentrations. $\mathrm{M}$ represents the molecular weight standard in $\mathrm{kDa}$. The lanes (1-9) contain 100, 80, 60, 40, 20, 10, 5, 2.5 , and $1 \mu \mathrm{g}$ of venom proteins, respectively.

The crude venom protein patterns observed in both gels show strong similarity with electrophoretic profiles from previous studies using Malaysian species [22,24]. A visual representation of the crude venom protein pattern provides an indication of possible geographic and species variation as well as illustrates the complexity of the sample being investigated. 


\subsection{Gel Filtration Separation of Crude Snake Venom Using Superdex G-75}

For the GF-ESI-LC-MS/MS based approach, C. rhodostoma and O. hannah venoms were subjected to a molecular weight separation according to Section 4.2.4. The proteins were eluted based on their molecular sizes, beginning with large molecular weight proteins. C. rhodostoma separation yielded six distinctive peaks and two minor fractions, i.e., a total of eight fractions (Figure 2). Similarly, O. hannah venom separation yielded six peaks and one minor fraction, with a total of seven fractions (Figure 3). All resulting fractions were pooled according to their individual peaks and subjected to in-solution tryptic digestion prior to characterization.

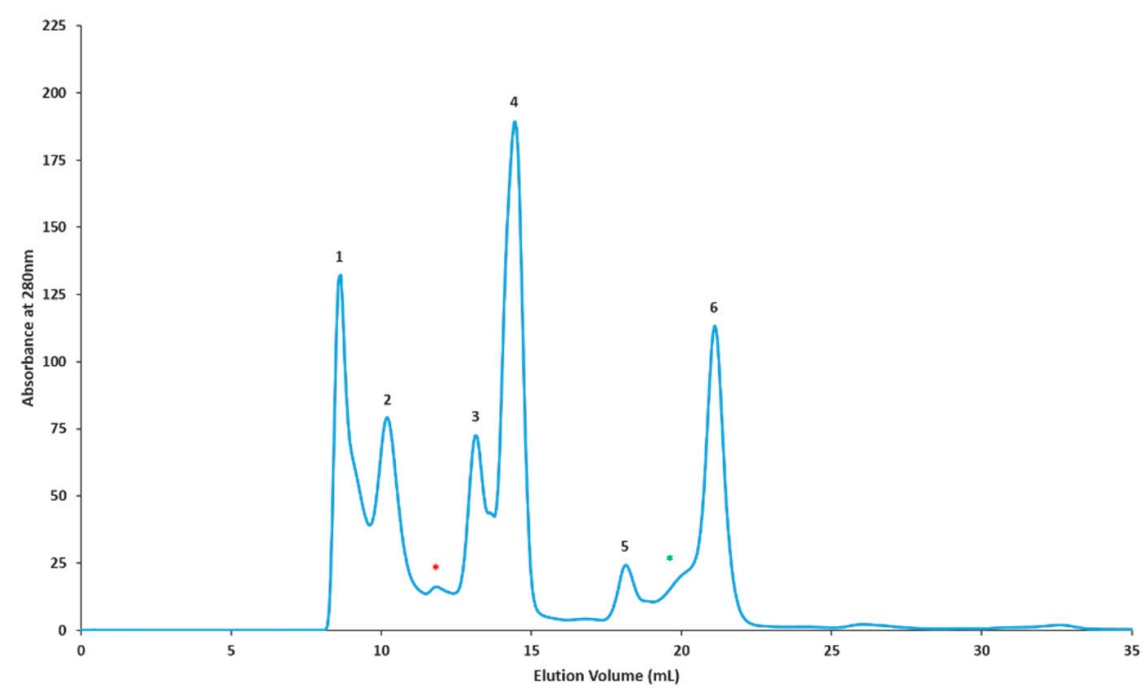

Figure 2. Superdex G75 chromatographic profile of Malaysian C. rhodostoma venom. Venom (10 mg) was dissolved in $10 \mathrm{mM}$ ammonium acetate $(250 \mu \mathrm{L}), \mathrm{pH} 7.0$ and loaded onto a pre-equilibrated column. Pre-equilibration and isocratic elution was carried out using the sample buffer. The chromatographic separation yielded six prominent peaks (1-6) and two minor fractions (marked *). Individual runs were repeated (at least 10 times). Fractions were pooled, desalted, concentrated, and subjected to in-solution tryptic digestion before analysis by ESI-LC-MS/MS.

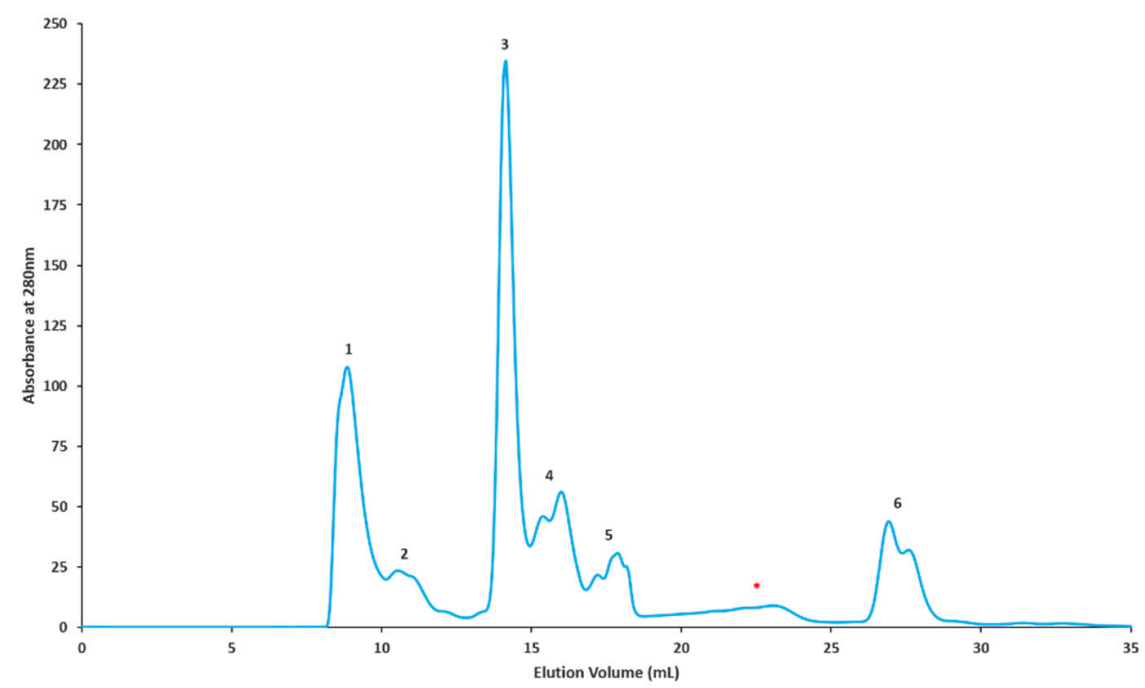

Figure 3. Superdex G75 chromatographic profile of Malaysian O. hannah venom. Venom (10 mg) was dissolved in $10 \mathrm{mM}$ ammonium acetate $(250 \mu \mathrm{L}), \mathrm{pH} 7.0$ and loaded onto a pre-equilibrated column. Pre-equilibration and isocratic elution was carried out using the sample buffer. The chromatographic separation yielded six prominent peaks (1-6) and one minor fraction (marked *). Individual runs were repeated (at least 10 times). Fractions were pooled, desalted, concentrated, and subjected to in-solution tryptic digestion before analysis by ESI-LC-MS/MS. 


\subsection{Snake Venom Proteomic Characterization Using Shotgun Approach (Shotgun-ESI-LC-MS/MS)}

Using the shotgun-ESI-LC-MS/MS approach, a total of 47 proteins belonging to 12 snake venom protein families were identified in $C$. rhodostoma venom (Table 1). The major protein families categorized were c-type lectin/snaclec (CTL/snaclec), phosphodiesterase (PDE), PLA $2, \mathrm{SVMP}, 5^{\prime}$-nucleotidase (5'-NTD), and snake venom serine protease (SVSP), followed by minor flavin monoamine oxidase (FMO), phospholipase B (PLB), CRiSP, glutaminyl-peptide cyclotransferase (QPCT), Trysinogen, and Ankyrin protein families. The latter three proteins were solely identified using this approach. For O. hannah venom, 76 proteins were identified from 19 toxin families. Quantitatively, there were two prominent families that made up the majority of the total venom, 3FTx with 23 peptides, followed by SVMP with 21 peptides (Table 2). The minority of venom was made up of Kunitz-type, CRiSP, FMO, PDE, 5'-NTD, PLA 2 , nerve-growth factor (NGF), acetylcholinesterase (AChE), complement C3 homolog $(\mathrm{CC} 3 \mathrm{H})$, endonuclease, neprilysin, ohanin/vespryn, platelet-derived growth factor/vascular endothelial growth factor (PDGF/VEGF), and SVSP protein families. Some notable proteins identified included the presence of insulin growth factors, hepatocyte growth factor activator, and CTL/snaclec peptides in O. hannah venom, which will be discussed in detail below. $5^{\prime}$-NTD and neprilysin proteins were exclusively detected using this approach.

\subsection{Snake Venom Proteomic Characterization Using Gel Filtration Protein Fractions (GF-ESI-LC-MS/MS)}

All resulting peptides from digested individual chromatographic fractions were classified according to protein families as per the previous section. From eight chromatographic fractions obtained for $C$. rhodostoma venom, a total of 99 proteins belonging to 12 protein families were detected (Figure 2, Table 3). The C. rhodostoma protein families were predominantly comprised of SVMPs as well as SVSPs and PDEs, while others families such as FMO, CTL/snaclec, PLA 2 , PLB, NGF, $5^{\prime}$-NTD, endonuclease, and CRiSP, were represented by lesser numbers of peptides. Of interest, the aminopeptidase protein family was newly discovered in $C$. rhodostoma venom using this proteomic approach. Other proteins not identified using the shotgun technique included endonucleases and NGFs (Table 3). For O. hannah venom, 150 proteins from 18 major families were observed for the seven chromatographic fractions (Figure 3, Table 4). The OH venom families consisted of 3FTx, SVMP, PLA 2 , CRiSP, PDE, Complement C3, Kunitz-type, Insulin, SVGF, SVSP, ohanin/vespryn, FMO, endonuclease, $\mathrm{CTL} /$ snaclec, AChE, NGF, PDGF/VEGF, and PLB. Interestingly, the presence of the single PLB peptide in the venom was detected only using this proteomic approach. 
Table 1. List of proteins identified from Malaysian C. rhodostoma venom using the shotgun-ESI-LC-MS/MS technique. Refer to Supplementary File (Table S1) for complete proteomic data and abbreviations lists.

\begin{tabular}{|c|c|c|c|c|c|}
\hline Protein Family & Protein Description & No. of Proteins & Protein Accession No. & No. of Peptides & No. of Unique Peptides \\
\hline \multirow{5}{*}{$5^{\prime}$-NTD } & $5^{\prime}$ nucleotidase (P. flavoviridis) & \multirow{5}{*}{5} & T2HRS9 & 4 & 2 \\
\hline & 5-nucleotidase (P. elegans) & & A0A077L6M5 & 4 & 2 \\
\hline & $5^{\prime}$ nucleotidase (P. flavoviridis) & & A0A077L7M9 & 4 & 2 \\
\hline & Snake venom $5^{\prime}$-nucleotidase (A. piscivorus) & & A0A194APL9 & 3 & 2 \\
\hline & BATXNUC1 (B. atrox) & & A0A1L8D667 & 3 & 2 \\
\hline CRiSP & Cysteine-rich secretory protein LCCL 2 (C. adamanteus) & 1 & A0A0F7ZEB6 & 2 & 2 \\
\hline \multirow{12}{*}{ CTL/snaclec } & C-type lectin (A. piscivorus leucostoma) & \multirow{12}{*}{12} & G8FML6 & 4 & 4 \\
\hline & C-type lectin 2 (A. piscivorus) & & A0A194APP2 & 6 & 6 \\
\hline & C-type lectin APL (A. piscivorus piscivorus) & & P0DM36 & 4 & 4 \\
\hline & C-type lectin BjL (B. jararaca) & & Q9PRY7 & 4 & 4 \\
\hline & C-type lectin PAL (B. arietans) & & Q9PSN0 & 4 & 4 \\
\hline & Snaclec clone 2100755 (D. acutus) & & Q8JIV8 & 3 & 3 \\
\hline & Snaclec rhodocetin subunit alpha (C. rhodostoma) & & P81397 & 17 & 15 \\
\hline & Snaclec rhodocetin subunit beta (C. rhodostoma) & & P81398 & 15 & 14 \\
\hline & Snaclec rhodocetin subunit gamma (C. rhodostoma) & & D2YW39 & 6 & 4 \\
\hline & Snaclec rhodocetin subunit delta (C. rhodostoma) & & D2YW40 & 6 & 6 \\
\hline & Snaclec rhodocytin subunit alpha (C. rhodostoma) & & Q9I841 & 8 & 8 \\
\hline & Snaclec rhodocytin subunit beta (C. rhodostoma) & & Q9I840 & 14 & 13 \\
\hline \multirow{2}{*}{ FMO } & Amine oxidase (O. okinavensis) & \multirow[b]{2}{*}{2} & T2HQ57 & 18 & 2 \\
\hline & L-amino-acid oxidase (C. rhodostoma) & & P81382 & 53 & 34 \\
\hline \multirow{7}{*}{ PDE } & Cadam10_PDE-1 (C. adamanteus) & \multirow{7}{*}{7} & A0A1W7RBB0 & 6 & 2 \\
\hline & Ectonucleotide pyrophosphatase/phosphodiesterase 3 (C. horridus) & & T1DJT5 & 6 & 2 \\
\hline & Phosphodiesterase (C. horridus) & & T1D6P7 & 6 & 3 \\
\hline & Phosphodiesterase (C. adamanteus) & & A0A0F7Z2Q3 & 6 & 3 \\
\hline & Phosphodiesterase (S. miliarius barbouri) & & A0A194AS02 & 6 & 2 \\
\hline & Venom phosphodiesterase 1 (C. adamanteus) & & J3SEZ3 & 6 & 3 \\
\hline & Venom phosphodiesterase 2 (C. adamanteus) & & J3SBP3 & 6 & 3 \\
\hline \multirow{6}{*}{$\mathrm{PLA}_{2}$} & Acidic phospholipase $\mathrm{A}_{2} \mathrm{H} 1 \mathrm{E} 6$ (C. rhodostoma) & \multirow{6}{*}{6} & Q9PVF2 & 11 & 10 \\
\hline & Acidic phospholipase $\mathrm{A}_{2}$ S1E6-b (C. rhodostoma) & & Q9PVF0 & 6 & 5 \\
\hline & Acidic phospholipase $\mathrm{A}_{2}$ Ts-A4 (T. stejnegeri) & & Q6H3C7 & 11 & 10 \\
\hline & Basic phospholipase $\mathrm{A}_{2}$ W6D49 (C. rhodostoma) & & Q9PVF4 & 21 & 6 \\
\hline & Phospholipase $\mathrm{A}_{2}$ (C. rhodostoma) & & A0ÃH3U266 & 23 & 6 \\
\hline & Phospholipase $\mathrm{A}_{2}$ (T. sabahi) & & A0A0H3U232 & 3 & 2 \\
\hline \multirow{2}{*}{ PLB } & Phospholipase B (O. okinavensis) & \multirow[b]{2}{*}{2} & T2HQ75 & 3 & 2 \\
\hline & Phospholipase B (P. regius) & & A0A098LY74 & 5 & 3 \\
\hline QPCT & Glutaminyl-peptide cyclotransferase (A. contortrix contortrix) & 1 & A0A1W7RH88 & 2 & 2 \\
\hline
\end{tabular}


Table 1. Cont.

\begin{tabular}{|c|c|c|c|c|c|}
\hline Protein Family & Protein Description & No. of Proteins & Protein Accession No. & No. of Peptides & No. of Unique Peptides \\
\hline \multirow{5}{*}{ SVMP } & Metalloprotease, mRNA (G. intermedius) & \multirow{5}{*}{5} & A0A0C4ZNF1 & 5 & 2 \\
\hline & Snake venom metalloproteinase kistomin (C. rhodostoma) & & P0CB14 & 86 & 86 \\
\hline & Zinc metalloproteinase/disintegrin (C. rhodostoma) & & P30403 & 38 & 36 \\
\hline & Zinc metalloproteinase-disintegrin-like halysase (G. halys) & & Q8AWI5 & 4 & 2 \\
\hline & Zinc metalloproteinase-disintegrin-like HV1 (P. flavoviridis) & & Q90ZI3 & 4 & 2 \\
\hline \multirow{4}{*}{ SVSP } & Serine protease 1 (P. elegans) & \multirow{4}{*}{4} & A0A077LA46 & 3 & 2 \\
\hline & Thrombin-like enzyme ancrod (C. rhodostoma) & & P26324 & 21 & 20 \\
\hline & Thrombin-like enzyme ancrod-2 (C. rhodostoma) & & P47797 & 17 & 13 \\
\hline & Thrombin-like enzyme elegaxobin-2 (P. elegans) & & P84787 & 3 & 2 \\
\hline Trypsinogen & Trypsinogen homolog (B. jararaca) & 1 & Q9PUF3 & 3 & 3 \\
\hline Others & Ankyrin repeat-containing protein (A. contortrix contortrix) & 1 & A0A1W7RJF1 & 2 & 2 \\
\hline
\end{tabular}

Abbreviations: 5'-NTD: 5'-nucleotidase; CRiSP: Cysteine-rich secretory protein; CTL: C-type lectin; FMO: Flavin monoamine oxidase; PDE: Phosphodiesterase; PLA 2 : Phospholipase $\mathrm{A}_{2}$; PLB: Phospholipase B; QPCT: Glutaminyl-peptide cyclotransferase; SVMP: Snake venom metalloproteinase; SVSP: Snake venom serine protease.

Table 2. List of proteins identified in Malaysian O. hannah venom via the shotgun-ESI-LC-MS/MS technique. Refer to Supplementary File (Table S2) for complete proteomic data and abbreviations lists.

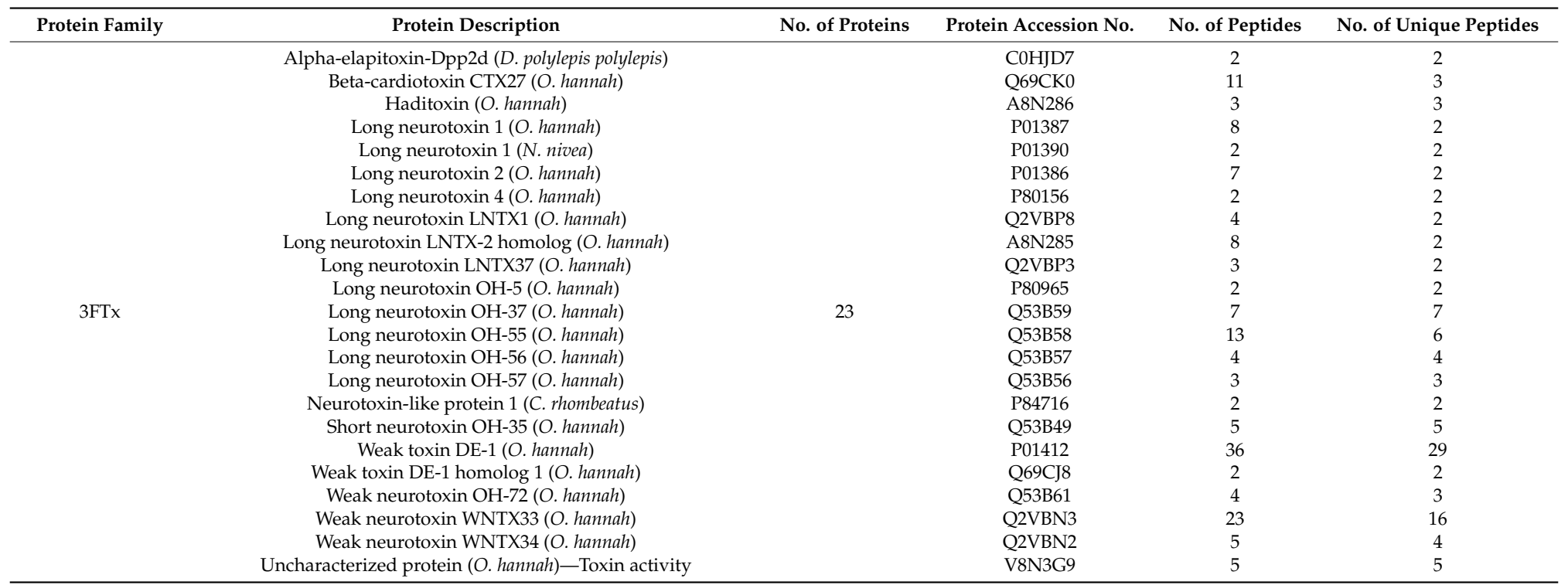


Table 2. Cont.

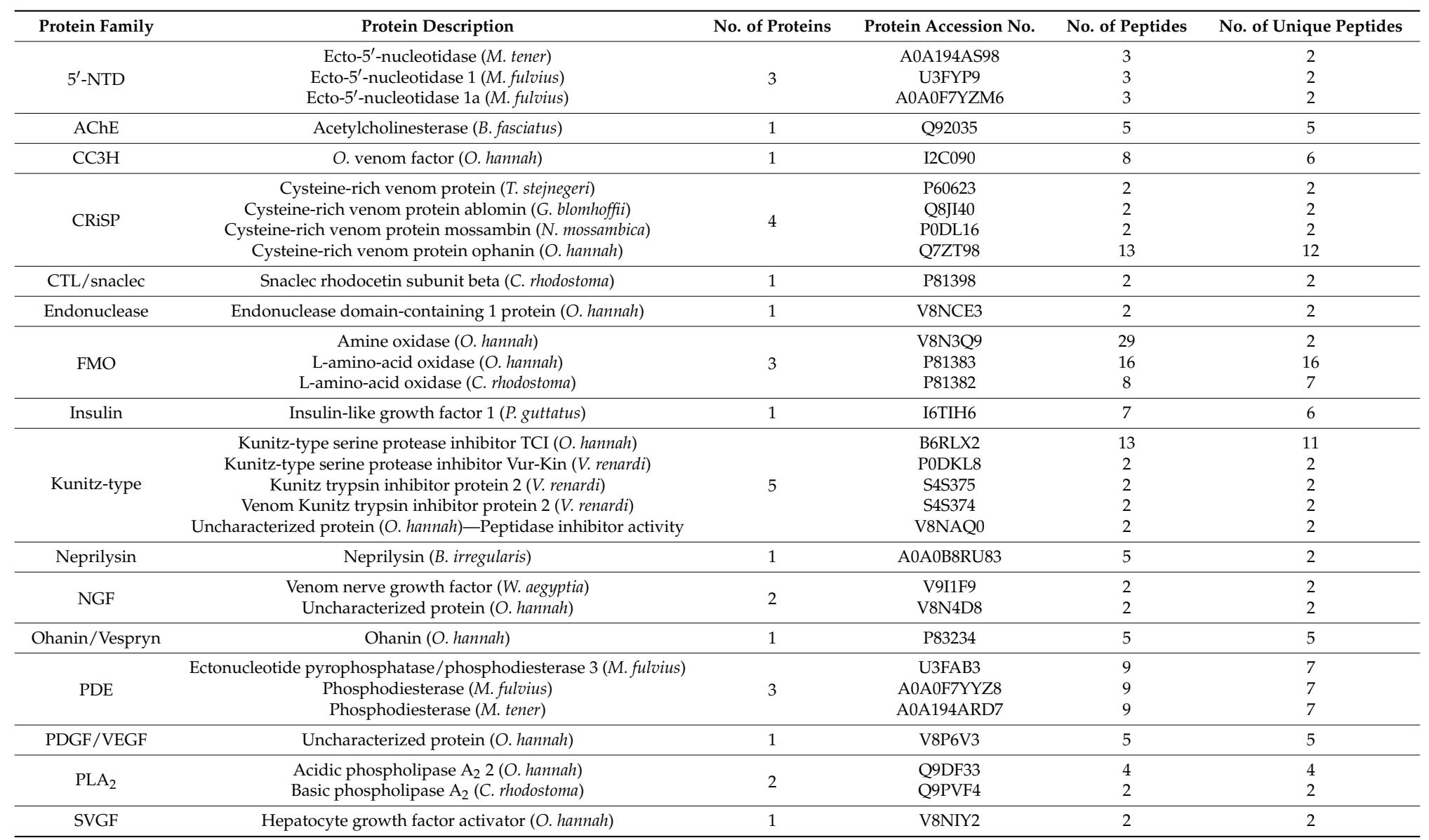


Table 2. Cont.

\begin{tabular}{|c|c|c|c|c|c|}
\hline Protein Family & Protein Description & No. of Proteins & Protein Accession No. & No. of Peptides & No. of Unique Peptides \\
\hline \multirow{15}{*}{ SVMP } & Metalloproteinase (type III) 2 (Hypsiglena sp.) & & A0A098M156 & 3 & 2 \\
\hline & Metalloproteinase type III 14b (Hypsiglena sp.) & & A0A098M219 & 3 & 2 \\
\hline & Metalloproteinase (type III) 14c (Hypsiglena sp.) & & A0A098M223 & 3 & 2 \\
\hline & Scutellatease-1 (O. scutellatus) & & B5KFV5 & 4 & 3 \\
\hline & Snake venom metalloproteinase BaP1 (B. asper) & & P83512 & 3 & 2 \\
\hline & Snake venom metalloproteinase BjussuMP-2 (B. jararacussu) & & Q7T1T4 & 3 & 2 \\
\hline & Snake venom metalloproteinase BmooMPalpha-I (B. moojeni) & & P85314 & 3 & 2 \\
\hline & Zinc metalloproteinase/disintegrin (B. asper) & & Q072L5 & 3 & 2 \\
\hline & Zinc metalloproteinase/disintegrin (B. insularis) & & Q5XUW8 & 3 & 2 \\
\hline & Zinc metalloproteinase/disintegrin (C. rhodostoma) & & P30403 & 5 & 5 \\
\hline & Zinc metalloproteinase-disintegrin-like atrase-A (N. atra) & & D5LMJ3 & 4 & 2 \\
\hline & Zinc metalloproteinase-disintegrin-like atrase-B (N. atra) & & D6PXE8 & 5 & 2 \\
\hline & Zinc metalloproteinase-disintegrin-like BjussuMP-1 (B. jararacussu) & & Q1PHZ4 & 3 & 2 \\
\hline & Zinc metalloproteinase-disintegrin-like kaouthiagin ( $N$. atra) & & D3TTC1 & 8 & 4 \\
\hline & Zinc metalloproteinase-disintegrin-like MTP9 (D. coronoides) & & F8RKV9 & 6 & 2 \\
\hline
\end{tabular}

Abbreviations: 3FTx: Three-finger toxin; 5'-NTD: 5'-nucleotidase; AChE: Acetylcholinesterase; CC3H: Complement C3 homolog; CRiSP: Cysteine-rich secretory protein; CTL: C-type lectin; FMO: Flavin monoamine oxidase; NGF: Nerve growth factor; PDE: Phosphodiesterase; PDGF/VEGF: Platelet-derived growth factor/vascular endothelial growth factor; PLA 2 : Phospholipase $\mathrm{A}_{2}$; SVGF: Snake venom growth factor; SVMP: Snake venom metalloproteinase; SVSP: Snake venom serine protease.

Table 3. List of proteins identified from Malaysian C. rhodostoma venom using the GF-LC-MS/MS technique. Refer to Supplementary File (Table S3) for complete proteomic data and abbreviations lists.

\begin{tabular}{|c|c|c|c|c|c|}
\hline Protein Family & Protein Description & No. of Proteins & Protein Accession No. & No. of Peptides & No. of Unique Peptides \\
\hline \multirow{4}{*}{$5^{\prime}$-NTD } & Snake venom $5^{\prime}$-nucleotidase (B. irregularis) & \multirow{4}{*}{4} & A0A0B8RXZ9 & 12 & 3 \\
\hline & $5^{\prime}$-nucleotidase (P. flavoviridis) & & T2HRS9 & 4 & 4 \\
\hline & $5^{\prime}$-nucleotidase (P. elegans) & & A0A077L6M5 & 5 & 4 \\
\hline & $5^{\prime}$-nucleotidase (P. flavooviridis) & & A0A077L7M9 & 4 & 4 \\
\hline \multirow{2}{*}{ Aminopeptidase } & Aminopeptidase (C. horridus) & \multirow{2}{*}{2} & T1DNX8 & 4 & 4 \\
\hline & Aminopeptidase (C. horridus) & & A0A0K8S2L4 & 4 & 4 \\
\hline CRiSP & Cysteine-rich secretory protein LCCL ... 2 (C. adamanteus) & 1 & A0A0F7ZEB6 & 9 & 9 \\
\hline
\end{tabular}


Table 3. Cont

\begin{tabular}{|c|c|c|c|c|c|}
\hline Protein Family & Protein Description & No. of Proteins & Protein Accession No. & No. of Peptides & No. of Unique Peptides \\
\hline \multirow{8}{*}{ CTL/snaclec } & Snaclec alboaggregin-D subunit alpha (T. albolabris) & \multirow{8}{*}{8} & P0DM38 & 4 & 3 \\
\hline & Snaclec rhodocetin subunit alpha (C. rhodostoma) & & P81397 & 58 & 57 \\
\hline & Snaclec rhodocetin subunit beta (C. rhodostoma) & & P81398 & 54 & 53 \\
\hline & Snaclec rhodocetin subunit gamma (C. rhodostoma) & & D2YW39 & 25 & 23 \\
\hline & Snaclec rhodocetin subunit delta (C. rhodostoma) & & D2YW40 & 22 & 22 \\
\hline & Snaclec rhodocytin subunit alpha (C. rhodostoma) & & Q9I841 & 12 & 11 \\
\hline & Snaclec rhodocytin subunit beta (C. rhodostoma) & & Q91840 & 10 & 8 \\
\hline & C-type lectin $12 \mathrm{a}$ (A. contortrix contortrix) & & A0A1W7RJZ7 & 7 & 7 \\
\hline \multirow{3}{*}{ Endonuclease } & Endonuclease domain-containing protein (O. hannah) & \multirow{3}{*}{3} & U3FCT9 & 2 & 2 \\
\hline & Endonuclease domain-containing protein (O. hannah) & & V8NCE3 & 2 & 2 \\
\hline & Deoxyribonuclease-2-alpha-like (C. adamanteus)-DNase & & J3RZ14 & 4 & 4 \\
\hline \multirow{8}{*}{ FMO } & Amine oxidase (O. okinavensis) & \multirow{8}{*}{8} & T2HQ57 & 40 & 4 \\
\hline & Amine oxidase (P. regius) & & A0A098LWS4 & 12 & 3 \\
\hline & Amine oxidase (P. guttatus) & & A0A098LX00 & 11 & 2 \\
\hline & L-amino-acid oxidase (C. rhodostoma) & & P81382 & 147 & 99 \\
\hline & L-amino acid oxidase (B. schlegelii) & & A0A024BTN9 & 46 & 10 \\
\hline & L-amino-acid oxidase (T. stejnegeri) & & Q6WP39 & 19 & 2 \\
\hline & L-amino-acid oxidase (L. muta) & & J7H670 & 15 & 2 \\
\hline & L-amino-acid oxidase (B. fasciatus) & & A8QL52 & 10 & 2 \\
\hline \multirow{4}{*}{ NGF } & Venom nerve growth factor (B. jararacussu) & \multirow{4}{*}{4} & Q90W38 & 3 & 2 \\
\hline & Nerve growth factor (P. flavoviridis) & & B1Q3K2 & 5 & 5 \\
\hline & Nerve growth factor (P. flavoviridis) & & A0A077L854 & 5 & 5 \\
\hline & BATXNGF1 (B. atrox) & & A0A1L8D608 & 3 & 2 \\
\hline \multirow{18}{*}{ PDE } & Cadam 10_PDE-1 (C. adamanteus) & \multirow{18}{*}{18} & A0A1W7RBB0 & 12 & 2 \\
\hline & Ectonucleotide pyrophosphatase/phosphodiesterase 3 (M. fulvius) & & U3FAB3 & 5 & 2 \\
\hline & Ectonucleotide pyrophosphatase/phosphodiesterase 3 (C. horridus) & & T1DJT5 & 12 & 3 \\
\hline & Phosphodiesterase (P. flavoviridis) & & T2HQA0 & 17 & 2 \\
\hline & Phosphodiesterase (P. flavoviridis) & & T2HRT4 & 17 & 2 \\
\hline & Phosphodiesterase (P. flavoviridis) & & T2HPD6 & 17 & 2 \\
\hline & Phosphodiesterase (P. flavoviridis) & & T2HP62 & 17 & 2 \\
\hline & Phosphodiesterase (M. fulvius) & & A0A0F7YYZ8 & 5 & 2 \\
\hline & Phosphodiesterase (M. tener) & & A0A194ARD7 & 5 & 2 \\
\hline & Phosphodiesterase (M. fulvius) & & A0A0F7YYZ8 & 3 & 2 \\
\hline & Phosphodiesterase (C. adamanteus) & & A0A0F7Z2Q3 & 12 & 3 \\
\hline & Phosphodiesterase (C. horridus) & & T1D6P7 & 12 & 3 \\
\hline & Phosphodiesterase (S. miliarius barbouri) & & A0A194AS02 & 12 & 3 \\
\hline & Phosphodiesterase (M. tener) & & A0A194ARD7 & 3 & 2 \\
\hline & Phosphodiesterase (M. rudis) & & A0A141DWM1 & 4 & 3 \\
\hline & Phosphodiesterase (M. lebetina) & & W8E7D1 & 4 & 2 \\
\hline & Venom phosphodiesterase 1 (C. adamanteus) & & J3SEZ3 & 12 & 2 \\
\hline & Venom phosphodiesterase 2 (C. adamanteus) & & J3SBP3 3 & 12 & 2 \\
\hline
\end{tabular}


Table 3. Cont

\begin{tabular}{|c|c|c|c|c|c|}
\hline Protein Family & Protein Description & No. of Proteins & Protein Accession No. & No. of Peptides & No. of Unique Peptides \\
\hline \multirow{10}{*}{$\mathrm{PLA}_{2}$} & Acidic phospholipase $\mathrm{A}_{2}$ (C. rhodostoma) & \multirow{10}{*}{10} & Q9PVF0 & 4 & 3 \\
\hline & Acidic phospholipase $\mathrm{A}_{2}$ (C. rhodostoma) & & Q9PVF1 & 16 & 4 \\
\hline & Acidic phospholipase $\mathrm{A}_{2}$ (C. rhodostoma) & & Q9PVF2 & 57 & 54 \\
\hline & Acidic phospholipase $\mathrm{A}_{2}$ (C. rhodostoma) & & Q9PVE9 & 6 & 2 \\
\hline & Acidic phospholipase $\mathrm{A}_{2}$ (O. hannah) & & Q9DF33 & 5 & 5 \\
\hline & Acidic phospholipase $\mathrm{A}_{2}$ (T. stejnegeri) & & Q6H3C7 & 34 & 32 \\
\hline & Basic phospholipase $\mathrm{A}_{2}$ W6D 49 (C. rhodostoma) & & Q9PVF4 & 25 & 11 \\
\hline & Phospholipase $\mathrm{A}_{2}$ (C. rhodostoma) & & A0Ä0H3U266 & 41 & 19 \\
\hline & Phospholipase $\mathrm{A}_{2}$ (C. atrox) & & A0A1J0R081 & 5 & 2 \\
\hline & Phospholipase $\mathrm{A}_{2} 1 \mathrm{c}(\mathrm{C}$. horridus $)$ & & A0A0K8RZ17 & 5 & 2 \\
\hline \multirow{6}{*}{ PLB } & Phospholipase B (C. adamanteus) & \multirow{6}{*}{6} & F8S101 & 16 & 5 \\
\hline & Phospholipase B (C. adamanteus) & & A0A0F7Z632 & 16 & 5 \\
\hline & Phospholipase B (P. regius) & & A0A098LY74 & 8 & 2 \\
\hline & Phospholipase B (P. guttatus) & & A0A098LWY9 & 4 & 2 \\
\hline & Phospholipase B (P. flavoviridis) & & T2HP68 & 7 & 5 \\
\hline & Phospholipase B (P. elegans) & & A0A077L7E7 & 7 & 5 \\
\hline \multirow{23}{*}{ SVMP } & AAV1 protein (D. acutus) & \multirow{23}{*}{23} & A0A0M4MEY5 & 4 & 2 \\
\hline & BATXSVMPIII (B. atrox) & & A0A1L8D5X9 & 3 & 2 \\
\hline & Disintegrin triflavin (P. flavoviridis) & & P21859 & 8 & 6 \\
\hline & Metalloprotease, mRNA (G. intermedius) & & A0A0C4ZNF1 & 8 & 2 \\
\hline & Metalloproteinase type III 2 (M. tener) & & A0A194AS47 & 3 & 2 \\
\hline & Metalloproteinase type III 2 (M. tener) & & A0A194AR91 & 7 & 3 \\
\hline & Metalloproteinase type III 2 (Hypsiglena sp.) & & A0A098M156 & 2 & 2 \\
\hline & Metalloproteinase type III 14c (Hypsiglena sp.) & & A0A098M223 & 2 & 2 \\
\hline & Metalloproteinase type III 5 (Hypsiglena sp.) & & A0A098M215 & 2 & 2 \\
\hline & p-III snake venom metalloprotease (M. ikaheca) & & A0A024AXX7 & 5 & 2 \\
\hline & Snake venom metalloproteinase kistomin (C. rhodostoma) & & P0СB14 & 198 & 197 \\
\hline & SVMP-disintegrin-like mocarhagin (N. mossambica) & & Q10749 & 8 & 4 \\
\hline & SVMP-Hop-15 (H. bungaroides) & & R4FJZ4 & 5 & 2 \\
\hline & Zinc metalloproteinase/disintegrin (C. rhodostoma) & & P30403 & 58 & 58 \\
\hline & Zinc metalloproteinase-disintegrin-like agkihagin (D. acutus) & & Q1PS45 & 8 & 2 \\
\hline & Zinc metalloproteinase-disintegrin-like atragin ( $N$. atra) & & D3TTC2 & 4 & 2 \\
\hline & Zinc metalloproteinase-disintegrin-like atrase-A ( $N$. atra $)$ & & D5LMJ3 & 4 & 2 \\
\hline & Zinc metalloproteinase-disintegrin-like BfMP (B. fasciatus) & & A8QL48 & 7 & 7 \\
\hline & Zinc metalloproteinase-disintegrin-like BmMP (B. multicinctus) & & A8QL49 & 7 & 7 \\
\hline & Zinc metalloproteinase-disintegrin-like cobrin (N. kaouthia) & & Q9PVK7 & 5 & 2 \\
\hline & Zinc metalloproteinase-disintegrin-like halysase (G. halys) & & Q8AWI5 & 8 & 2 \\
\hline & Zinc metalloproteinase-disintegrin-like HV1 (P. flavoviridis) & & Q90ZI3 & 9 & 2 \\
\hline & Zinc metalloproteinase-disintegrin-like ohanin (O. hannah) & & A3R0T9 & 12 & 12 \\
\hline
\end{tabular}


Table 3. Cont.

\begin{tabular}{|c|c|c|c|c|c|}
\hline Protein Family & Protein Description & No. of Proteins & Protein Accession No. & No. of Peptides & No. of Unique Peptides \\
\hline \multirow{12}{*}{ SVSP } & Snake venom serine protease catroxase (C. atrox) & \multirow{12}{*}{12} & Q8QHK2 & 3 & 2 \\
\hline & Snake venom serine proteinase (C. adamanteus) & & F8S116 & 3 & 2 \\
\hline & Serine protease ( $P$. flavoviridis) & & A0A077L6P3 & 12 & 2 \\
\hline & Serine proteinase 3 (A. piscivorus) & & A0A194APA8 & 3 & 2 \\
\hline & Serine proteinase $3 a$ (A. contortrix contortrix) & & A0A1W7RJX1 & 3 & 2 \\
\hline & Serine proteinase 4 (A. contortrix contortrix) & & A0A1W7RJU2 & 3 & 2 \\
\hline & Serine proteinase 9 (A. contortrix contortrix) & & A0A1W7RJUO & 3 & 2 \\
\hline & Serine proteinase 10 (C. horridus) & & T1DH10 & 5 & 2 \\
\hline & Serine proteinase $12 \mathrm{a}$ (A. piscivorus) & & A0A194APD3 & 3 & 2 \\
\hline & Thrombin-like enzyme ancrod (C. rhodostoma) & & P26324 & 64 & 59 \\
\hline & Thrombin-like enzyme ancrod-2 (C. rhodostoma) & & P47797 & 39 & 37 \\
\hline & Thrombin-like protein (A. piscivorus leucostoma) & & E9NX14 & 3 & 2 \\
\hline
\end{tabular}

$$
\text { TOTAL PROTEINS }
$$

Abbreviations: 5'-NTD: 5'-nucleotidase; CRiSP: Cysteine-rich secretory protein; CTL: C-type lectin; FMO: Flavin monoamine oxidase; NGF: Nerve growth factor; PDE: Phosphodiesterase; $\mathrm{PLA}_{2}$ : Phospholipase $\mathrm{A}_{2}$; PLB: Phospholipase B; SVMP: Snake venom metalloproteinase; SVSP: Snake venom serine protease.

Table 4. List of proteins identified from Malaysian O. hannah venom using the GF-LC-MS/MS technique. Refer to Supplementary File (Table S4) for complete proteomic data and abbreviations lists.

\begin{tabular}{|c|c|c|c|c|c|}
\hline Protein Family & Protein Description & No. of Proteins & Protein Accession No. & No. of Peptides & No. of Unique Peptides \\
\hline \multirow{22}{*}{ 3FTx } & Alpha-cobratoxin (N. kaouthia) & \multirow{22}{*}{51} & P01391 & 4 & 2 \\
\hline & Alpha-elapitoxin-Dpp2d (D. polylepis polylepis) & & COHJD7 & 3 & 2 \\
\hline & Alpha-elapitoxin-Dv2a (D. viridis) & & P01395 & 3 & 2 \\
\hline & Alpha-elapitoxin-Nno2a (N. oxiana) & & P01382 & 5 & 4 \\
\hline & Alpha-elapitoxin-Oh2b (O. hannah) & & P82662 & 15 & 4 \\
\hline & Haditoxin (O. hannah) & & A8N286 & 16 & 16 \\
\hline & Kappa-6-bungarotoxin (B. multicinctus) & & Q9W729 & 3 & 2 \\
\hline & Long neurotoxin 1 (A. superbus) & & A8S6A8 & 3 & 2 \\
\hline & Long neurotoxin 1 (N. annulata annulata) & & P34074 & 9 & 2 \\
\hline & Long neurotoxin 1 (N. haje haje) & & P25674 & 9 & 4 \\
\hline & Long neurotoxin 1 (N. nivea) & & P01390 & 7 & 4 \\
\hline & Long neurotoxin 1 (O. hannah) & & P01387 & 26 & 6 \\
\hline & Long neurotoxin 2 (O. hannah) & & P01386 & 5 & 5 \\
\hline & Long neurotoxin 2 (N. melanoleuca) & & P01388 & 8 & 3 \\
\hline & Long neurotoxin 3 (O. hannah) & & P07526 & 5 & 2 \\
\hline & Long neurotoxin 4 (O. hannah) & & P80156 & 14 & 3 \\
\hline & Long neurotoxin LILong (L. laticaudata) & & Q7T2I3 & 3 & 2 \\
\hline & Long neurotoxin OH-17 (O. hannah) & & Q53B54 & 8 & 2 \\
\hline & Long neurotoxin OH-37 (O. hannah) & & Q53B59 & 20 & 9 \\
\hline & Long neurotoxin OH-55 (O. hannah) & & Q53B58 & 44 & 21 \\
\hline & Long neurotoxin OH-56 (O. hannah) & & Q53B57 & 18 & 15 \\
\hline & Long neurotoxin OH-57 (O. hannah) & & Q53B56 & 7 & 5 \\
\hline
\end{tabular}


Table 4. Cont.

\begin{tabular}{|c|c|c|c|c|c|}
\hline Protein Family & Protein Description & No. of Proteins & Protein Accession No. & No. of Peptides & No. of Unique Peptides \\
\hline \multirow{29}{*}{ 3FTx } & Long neurotoxin LNTX1 (O. hannah) & \multirow{29}{*}{51} & Q2VBP8 & 13 & 5 \\
\hline & Long neurotoxin LNTX-2 (O. hannah) & & A8N285 & 14 & 3 \\
\hline & Long neurotoxin LNTX8 (O. hannah) & & Q2VBP6 & 21 & 3 \\
\hline & Long neurotoxin LNTX22 (O. hannah) & & Q2VBP5 & 5 & 3 \\
\hline & Non-conventional three finger toxin isoform (B. flaviceps) & & D5J9P9 & 4 & 2 \\
\hline & Oxiana weak toxin (N. oxiana) & & P85520 & 3 & 3 \\
\hline & Short neurotoxin $\mathrm{OH}-35$ (O. hannah) & & Q53B49 & 5 & 5 \\
\hline & Three-finger toxin (B. multicinctus) & & E2IU12 & 2 & 2 \\
\hline & Three-finger toxin (B. multicinctus) & & E2IU14 & 2 & 2 \\
\hline & Weak neurotoxin (N. N.) & & P29181 & 2 & 2 \\
\hline & Weak neurotoxin OH-72 (O. hannah) & & Q53B61 & 13 & 10 \\
\hline & Weak neurotoxin WNTX33 (O. hannah) & & Q2VBN3 & 65 & 55 \\
\hline & Weak neurotoxin WNTX34 (O. hannah) & & Q2VBN2 & 13 & 10 \\
\hline & Weak neurotoxin 7 (N. N.) & & P29181 & 4 & 3 \\
\hline & Weak neurotoxin 10 (N. sputatrix) & & Q802B2 & 2 & 2 \\
\hline & Weak toxin CM-11 (N. haje haje) & & P01401 & 3 & 3 \\
\hline & Weak toxin DE-1 (O. hannah) & & P01412 & 117 & 110 \\
\hline & Weak toxin DE-1 homolog 1 (O. hannah) & & Q69CJ8 & 12 & 12 \\
\hline & Weak toxin S4C11 (N. melanoleuca) & & P01400 & 3 & 3 \\
\hline & Putative long neurotoxin (A. labialis) & & B2BRQ8 & 3 & 2 \\
\hline & Putative long neurotoxin (A. labialis) & & B2BRQ9 & 3 & 2 \\
\hline & Putative long neurotoxin (A. labialis) & & B2BRR0 & 3 & 2 \\
\hline & Putative long neurotoxin (A. labialis) & & B2BRR1 & 3 & 2 \\
\hline & Putative long neurotoxin (A. labialis) & & B2BRR2 & 3 & 2 \\
\hline & Putative long neurotoxin (A. labialis) & & B2BRR3 & 3 & 2 \\
\hline & Putative long neurotoxin (A. labialis) & & B2BRR6 & 3 & 2 \\
\hline & Putative long neurotoxin (A. labialis) & & B2BRR8 & 3 & 2 \\
\hline & Uncharacterized protein (O. hannah)-Toxin activity & & V8N389 & 7 & 5 \\
\hline & Uncharacterized protein (O. hannah) - Toxin activity & & V8N3G9 & 5 & 5 \\
\hline AChE & Carboxylic ester hydrolase (S. fasciata) & 1 & R4FKE6 & 2 & 2 \\
\hline \multirow{7}{*}{$\mathrm{CC} 3 \mathrm{H}$} & Complement-depleting factor (O. hannah) & \multirow{7}{*}{7} & A8QL55 & 8 & 8 \\
\hline & O. venom factor (O. hannah) & & $\mathrm{I} 2 \mathrm{C} 090$ & 34 & 23 \\
\hline & Venom factor (C. horridus) & & T1E3W8 & 2 & 2 \\
\hline & Venom factor (Sistrurus catenatus tergeminus) & & A0A194APJ4 & 2 & 2 \\
\hline & Venom factor (Agkistrodon piscivorus) & & A0A194ARG1 & 2 & 2 \\
\hline & Venom factor (C. adamanteus) & & A0A0F7Z1I7 & 2 & 2 \\
\hline & Venom factor (C. adamanteus) & & J3S836 & 2 & 2 \\
\hline
\end{tabular}


Table 4. Cont.

\begin{tabular}{|c|c|c|c|c|c|}
\hline Protein Family & Protein Description & No. of Proteins & Protein Accession No. & No. of Peptides & No. of Unique Peptides \\
\hline \multirow{13}{*}{ CRiSP } & Cysteine-rich venom protein (P. olfersii) & \multirow{13}{*}{13} & Q09GJ9 & 3 & 2 \\
\hline & Cysteine-rich venom protein mossambin (N. mossambica) & & P0DL16 & 9 & 2 \\
\hline & Cysteine-rich venom protein ophanin (O. hannah) & & Q7ZT98 & 44 & 14 \\
\hline & Cysteine-rich venom protein TRI1 (T. biscutatus) & & Q2XXP4 & 4 & 2 \\
\hline & Cysteine-rich secretory protein (O. okinavensis) & & T2HPR8 & 7 & 2 \\
\hline & Cysteine-rich secretory protein (P. chamissonis) & & A0A0B4SXI8 & 2 & 2 \\
\hline & Cysteine-rich secretory protein Az-CRP (A. feae $)$ & & F2Q6E3 & 6 & 2 \\
\hline & Cysteine-rich secretory protein Bc-CRP (B. schlegelii) & & F2Q6E4 & 7 & 2 \\
\hline & Cysteine-rich secretory protein Bc-CRPa (B. candidus) & & F2Q6G3 & 3 & 3 \\
\hline & Cysteine-rich secretory protein $\mathrm{Bc}-\mathrm{CRPb}$ (B. candidus) & & F2Q6G2 & 2 & 2 \\
\hline & Cysteine-rich secretory protein $1 \mathrm{~b}$ (B. irregularis) & & A0A0B8RZW7 & 3 & 2 \\
\hline & Cysteine-rich secretory protein 1c (B. irregularis) & & A0A0B8RYV8 & 3 & 2 \\
\hline & Uncharacterized protein (O. hannah) & & V8N8B4 & 35 & 5 \\
\hline $\mathrm{CTL} /$ snaclec & Snaclec rhodocetin subunit alpha (C. rhodostoma) & 1 & P81397 & 2 & 2 \\
\hline \multirow[b]{2}{*}{ Endonuclease } & Endonuclease domain-containing protein (O. hannah) & \multirow[b]{2}{*}{2} & V8NCE3 & 3 & 2 \\
\hline & Endonuclease domain-containing protein (O. hannah) & & V8N4Y2 & 3 & 2 \\
\hline \multirow[b]{2}{*}{ FMO } & Amine oxidase (O. hannah) & \multirow[b]{2}{*}{2} & V8N3Q9 & 52 & 8 \\
\hline & L-amino-acid oxidase (O. hannah) & & P81383 & 59 & 15 \\
\hline \multirow{5}{*}{ Insulin } & Insulin-like growth factor 1 (P. guttatus) & \multirow{5}{*}{5} & I6TIH6 & 19 & 15 \\
\hline & Insulin-like growth factor I (O. hannah) & & V8NHJ8 & 7 & 5 \\
\hline & Insulin-like growth factor 1 (C. helena) & & I6S9K4 & 7 & 2 \\
\hline & Insulin-like growth factor 1 (T. elegans) & & I6T666 & 9 & 9 \\
\hline & Uncharacterized protein (O. hannah) - Hormone activity & & V8N2J2 & 4 & 4 \\
\hline \multirow{6}{*}{ Kunitz-type } & Kunitz-type serine protease inhibitor (O. hannah) & \multirow{6}{*}{6} & P82966 & 7 & 3 \\
\hline & Kunitz-type serine protease inhibitor TCI (O. hannah) & & B6RLX2 & 31 & 27 \\
\hline & Kunitz-type serine protease inhibitor Vur-KIn (V. renardi) & & P0DKL8 & 4 & 3 \\
\hline & Kunitz trypsin inhibitor protein 2 (V. renardi) & & S4S375 & 4 & 3 \\
\hline & Venom Kunitz trypsin inhibitor protein 2 (V. renardi) & & S4S374 & 4 & 3 \\
\hline & Uncharacterized protein (O. hannah) - Peptidase inhibitor activity & & V8NAQ0 & 4 & 4 \\
\hline NGF & Uncharacterized protein (O. hannah) & 1 & V8N4D8 & 2 & 2 \\
\hline \multirow{2}{*}{ Ohanin/Vespryn } & Ohanin (O. hannah) & \multirow[b]{2}{*}{2} & P83234 & 22 & 17 \\
\hline & Thaicobrin (N. kaouthia) & & P82885 & 2 & 2 \\
\hline \multirow{11}{*}{ PDE } & Cadam 10_PDE-1 (C. adamanteus) & \multirow{11}{*}{11} & A0A1W7RBB0 & 3 & 2 \\
\hline & Ectonucleotide pyrophosphatase/phosphodiesterase 3 (M. fulvius) & & U3FAB3 & 11 & 11 \\
\hline & Ectonucleotide pyrophosphatase/phosphodiesterase 3 (C. horridus) & & T1DJT5 & 3 & 2 \\
\hline & Phosphodiesterase (M. tener) & & A0A194ARD7 & 11 & 11 \\
\hline & Phosphodiesterase (M. fulvius) & & A0A0F7YYZ8 & 11 & 11 \\
\hline & Phosphodiesterase (C. horridus) & & T1D6P7 & 3 & 2 \\
\hline & Phosphodiesterase (C. adamanteus) & & A0A0F7Z2Q3 & 3 & 2 \\
\hline & Phosphodiesterase (O. okinavensis) & & U3TBJ5 & 3 & 2 \\
\hline & Phosphodiesterase (O. okinavensis) & & U3TAI7 & 3 & 2 \\
\hline & Venom phosphodiesterase 1 (C. adamanteus) & & J3SEZ3 & 3 & 2 \\
\hline & Venom phosphodiesterase 2 (C. adamanteus) & & J3SBP3 & 3 & 2 \\
\hline PDGF/VEGF & Uncharacterized protein (O. hannah) & 1 & V8P6V3 & 7 & 7 \\
\hline
\end{tabular}


Table 4. Cont.

\begin{tabular}{|c|c|c|c|c|c|}
\hline Protein Family & Protein Description & No. of Proteins & Protein Accession No. & No. of Peptides & No. of Unique Peptides \\
\hline \multirow{8}{*}{$\mathrm{PLA}_{2}$} & Acidic phospholipase $\mathrm{A}_{2} 2$ (O. hannah) & \multirow{8}{*}{8} & Q9DF33 & 54 & 49 \\
\hline & Acidic phospholipase $\mathrm{A}_{2}$ (O. hannah) & & Q9DF56 & 20 & 17 \\
\hline & Acidic phospholipase $\mathrm{A}_{2} \mathrm{KBf}$-grIB (B. fasciatus) & & P0C551 & 2 & 2 \\
\hline & Phospholipase $\mathrm{A}_{2} 12$ (M. fulvius) & & U3FVG1 & 5 & 2 \\
\hline & Phospholipase $\mathrm{A}_{2} 23$ (M. fulvius) & & U3FVF5 & 5 & 2 \\
\hline & $\mathrm{PLA}_{2}$ (IB)-Tri1 (T. biscutatus) & & A7X418 & 5 & 3 \\
\hline & Secretory phospholipase $\mathrm{A}_{2}$ (Group 10) (O. hannah) & & V8PDP0 & 2 & 2 \\
\hline & Uncharacterized protein (O. hannah) & & V8N1D8 & 2 & 2 \\
\hline PLB & Phospholipase B-like 1 (O. hannah) & 1 & V8ND68 & 9 & 9 \\
\hline \multirow{3}{*}{ SVGF } & Hepatocyte growth factor activator (O. hannah) & \multirow{3}{*}{3} & V8NIY2 & 2 & 2 \\
\hline & Macrophage colony-stimulating factor 1 (O. hannah) & & V8NW35 & 3 & 3 \\
\hline & Tumor necrosis factor receptor (O. hannah) & & V8P0T5 & 5 & 5 \\
\hline \multirow{26}{*}{ SVMP } & Asrin (A. superbus) & \multirow{26}{*}{33} & A6XJS7 & 11 & 6 \\
\hline & BATXSVMPII2 (B. atrox) & & A0A1L8D6A9 & 4 & 2 \\
\hline & BATXSVMPII1 (B. atrox) & & A0A1L8D600 & 4 & 2 \\
\hline & BATXSVMPII3 (B. atrox) & & A0A1L8D5Z6 & 4 & 2 \\
\hline & BATXSVMPIII9 (B. atrox) & & A0A1L8D641 & 4 & 2 \\
\hline & Metalloproteinase (A. andersonii) & & Q9PT47 & 6 & 2 \\
\hline & Metalloproteinase (D. vestigiata) & & B5G6F7 & 6 & 2 \\
\hline & Metalloprotease BOJUMET III (B. jararacussu) & & Q7T1T3 & 4 & 2 \\
\hline & Metalloproteinase PIII (T. gracilis) & & V5IWF4 & 2 & 2 \\
\hline & Metalloproteinase type III 2 (Hypsiglena sp.) & & A0A098M156 & 6 & 2 \\
\hline & Metalloproteinase type III 14b (Hypsiglena sp.) & & A0A098M219 & 7 & 4 \\
\hline & Metalloproteinase type III 14c (Hypsiglena sp.) & & A0A098M223 & 5 & 2 \\
\hline & Metalloproteinase type III 1 (M. fulvius) & & U3EPC7 & 5 & 5 \\
\hline & Metalloproteinase type III 2 (M. tener) & & A0A194AS47 & 16 & 4 \\
\hline & Metalloproteinase type III $2 \mathrm{~b}$ (M. tener) & & A0A0F7YYV1 & 5 & 2 \\
\hline & Scutellatease-1 (O. scutellatus) & & B5KFV5 & 13 & 7 \\
\hline & SVMP-disintegrin-like mocarhagin (N. mossambica) & & Q10749 & 9 & 5 \\
\hline & Snake venom metalloproteinase kistomin (C. rhodostoma) & & P0CB14 & 4 & 4 \\
\hline & Snake venom metalloprotease (P.olfersii) & & C6JUN3 & 4 & 2 \\
\hline & Snake venom metalloprotease ( $P$. olfersii) & & C6JUN4 & 4 & 2 \\
\hline & Stephensease-1 (H. stephensii) & & B5KFV4 & 8 & 2 \\
\hline & SVMP-Aca-4 (A. wellsi) & & R4G2D3 & 11 & 4 \\
\hline & SVMP-Den-9 (D. devisi) & & R4FIC4 & 15 & 2 \\
\hline & SVMP-Ech-32 (E. curta) & & R4FJM6 & 6 & 2 \\
\hline & SVMP-Fur-1 (F. ornata) & & R4G2G3 & 4 & 2 \\
\hline & SVMP-Hem-2 (H. signata) & & R4G2W9 & 8 & 3 \\
\hline
\end{tabular}


Table 4. Cont.

\begin{tabular}{|c|c|c|c|c|c|}
\hline Protein Family & Protein Description & No. of Proteins & Protein Accession No. & No. of Peptides & No. of Unique Peptides \\
\hline \multirow{7}{*}{ SVMP } & SVMP-Hop-14 (H. bungaroides) & \multirow{7}{*}{33} & R4FIM1 & 5 & 3 \\
\hline & Zinc metalloproteinase-disintegrin-like atrase-A (N. atra) & & D5LMJ3 & 14 & 3 \\
\hline & Zinc metalloproteinase-disintegrin-like atrase-B (N. atra) & & D6PXE8 & 9 & 3 \\
\hline & Zinc metalloproteinase-disintegrin-like cobrin (N. kaouthia) & & Q9PVK7 & 7 & 2 \\
\hline & Zinc metalloproteinase-disintegrin-like kaouthiagin-like (N. atra) & & D3TTC1 & 9 & 3 \\
\hline & Zinc metalloproteinase-disintegrin-like MTP4 (D. coronoides) & & F8RKW1 & 11 & 3 \\
\hline & Zinc metalloproteinase-disintegrin-like ohanin (O. hannah) & & A3R0T9 & 19 & 10 \\
\hline \multirow[b]{2}{*}{ SVSP } & Alpha and beta fibrinogenase OhS1 (O. hannah) & \multirow[b]{2}{*}{2} & A8QL56 & 6 & 4 \\
\hline & Neuroendocrine convertase 1 (O. hannah) & & V8P1Y2 & 3 & 3 \\
\hline
\end{tabular}

$$
\text { TOTAL PROTEINS } 150
$$

Abbreviations: 3FTx: Three-finger toxin; AChE: Acetylcholinesterase; CC3H: Complement C3 homolog; CRiSP: Cysteine-rich secretory protein; CTL: C-type lectin; FMO: Flavin monoamine oxidase; NGF: Nerve growth factor; PDE: Phosphodiesterase; PDGF/VEGF: Platelet-derived growth factor/vascular endothelial growth factor; PLA 2 : Phospholipase $\mathrm{A}_{2}$; PLB:

Phospholipase B; SVGF: Snake venom growth factor; SVMP: Snake venom metalloproteinase; SVSP: Snake venom serine protease. 


\subsection{Summary of Identified C. rhodostoma and O. hannah Snake Venom Proteins}

To obtain an overview of the major protein classes in Malaysian C. rhodostoma and O. hannah snake venoms, we combined two proteomic approaches that have made it possible to detect a higher number of proteins than previously reported. Our proteomic analysis revealed 114 proteins, belonging to 15 major protein families, for C. rhodostoma venom, and 176 proteins, belonging to 20 protein families, for O. hannah venom (Figures 4-6, Table 5). Amongst these identified protein families are several new, previously undiscovered proteins for these venoms. These include aminopeptidase, glutaminyl-peptide cyclotransferase, and Ankyrin repeat for C. rhodostoma venom and insulin, CTL/snaclec, and SVGF (hepatocyte growth factor activator, macrophage colony stimulating factor, tumor necrosis factor receptor) for O. hannah venom (Table 5).

Table 5. Relative abundance of snake venom toxin families identified in Malaysian C. rhodostoma and O. hannah venoms. The relative abundance is presented in percentages (\%) alongside the number of protein subtypes included in parentheses. Major species-specific families are highlighted in bold (CR, blue; $\mathrm{OH}$, red).

\begin{tabular}{|c|c|c|}
\hline Snake Venom Protein Families & Calloselasma rhodostoma & Ophiophagus hannah \\
\hline 3FTx & ND & $31(55)$ \\
\hline Complement C3 Homolog & ND & $4(7)$ \\
\hline Kunitz-type & ND & $3(6)$ \\
\hline Insulin & ND & $3(5)$ \\
\hline SVGF & ND & $2(3)$ \\
\hline $\mathrm{AChE}$ & ND & $1(2)$ \\
\hline Ohanin/Vespryn & ND & $1(2)$ \\
\hline Neprilysin & ND & $1(1)$ \\
\hline PDGF/VEGF & ND & $1(1)$ \\
\hline SVMP & $20(23)$ & $25(44)$ \\
\hline PDE & $16(18)$ & $6(11)$ \\
\hline SVSP & $12(14)$ & $1(2)$ \\
\hline CTL/snaclec & $12(14)$ & $1(2)$ \\
\hline $\mathrm{PLA}_{2}$ & $10(11)$ & $5(9)$ \\
\hline FMO & $7(8)$ & $2(3)$ \\
\hline PLB & $6(7)$ & $1(1)$ \\
\hline $5^{\prime}-\mathrm{NTD}$ & $5(6)$ & $2(3)$ \\
\hline NGF & $4(4)$ & $1(2)$ \\
\hline Endonuclease & $3(3)$ & $1(2)$ \\
\hline CRiSP & $1(1)$ & $9(15)$ \\
\hline Aminopeptidase & $2(2)$ & ND \\
\hline QPCT & $1(1)$ & ND \\
\hline Trypsinogen & $1(1)$ & ND \\
\hline Others (ANK) & $1(1)$ & ND \\
\hline TOTAL & $100(114)$ & $100(176)$ \\
\hline
\end{tabular}

Abbreviations: 3FTx: Three-finger toxin; 5'-NTD: 5'-nucleotidase; AChE: Acetylcholinesterase; ANK: Ankyrin repeat proteins; CTL: C-type lectin; CRiSP: Cysteine-rich secretory protein; FMO: Flavin monoamine oxidase; NGF: Nerve growth factor; PDE: Phosphodiesterase; PDGF/VEGF: Platelet-derived growth factor/vascular endothelial growth factor; PLA $_{2}$ : Phospholipase $\mathrm{A}_{2}$; PLB: Phospholipase B; QPCT: Glutaminyl-peptide cyclotransferase; SVGF: Snake venom growth factor; SVMP: Snake venom metalloproteinase; SVSP: Snake venom serine protease; ND: not determined.

Using the shotgun approach, a total of 47 and 76 proteins were detected in CR and OH venoms, whereby 15 and 26 proteins were exclusively identified using the shotgun approach. In comparison, 99 and 150 proteins were identified using the gel-filtration approach, with 67 and 100 proteins being detected exclusively with this approach (Figure 4). Although the most common and widely used liquid chromatography separation for venom proteome profiling is reverse-phase C18 HPLC, we have utilized a molecular weight based separation to try to overcome some potential difficulties in the elution of low abundant large molecular weight proteins $[25,26]$. It appears that prior protein separation, 
together with the use of the unconventional molecular weight based separation, does indeed allow for decomplexation of crude venom proteins that has enabled a higher number of proteins to be detected.

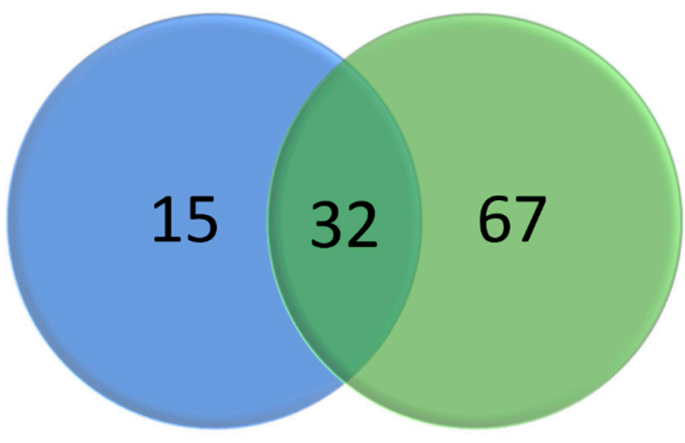

(a)

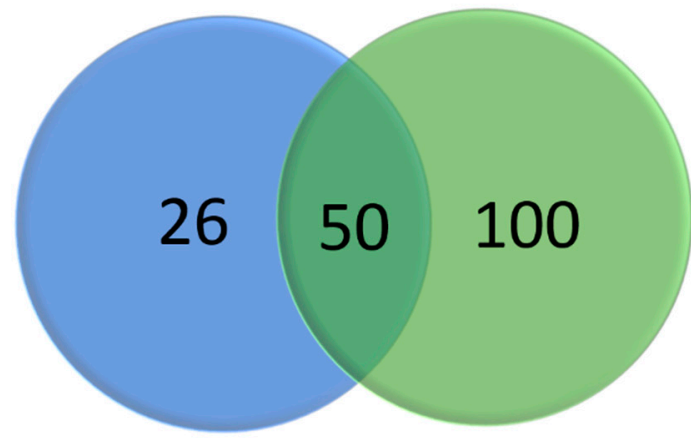

(b)

Figure 4. A two-way Venn diagram depicting the overlap of the number of proteins identified by two proteomic strategies for (a) C. rhodostoma and (b) O. hannah venoms. The strategies employed crude venom and gel filtration fractions to comprehensively characterize the entire venom proteome. The proteomic analyses were performed via a combination of nanoflow liquid chromatography coupled with electrospray tandem mass spectrometry (ESI-LC-MS/MS) and automated de novo sequencing. 32 and 50 proteins were common between the two data sets for C. rhodostoma and O. hannah, respectively. Both venoms demonstrated a higher number of proteins identified in the gel filtration strategy compared to the crude venom strategy. The identified proteins were matched using the UniProt database (Serpentes) and subsequently categorized according to individual toxin family.

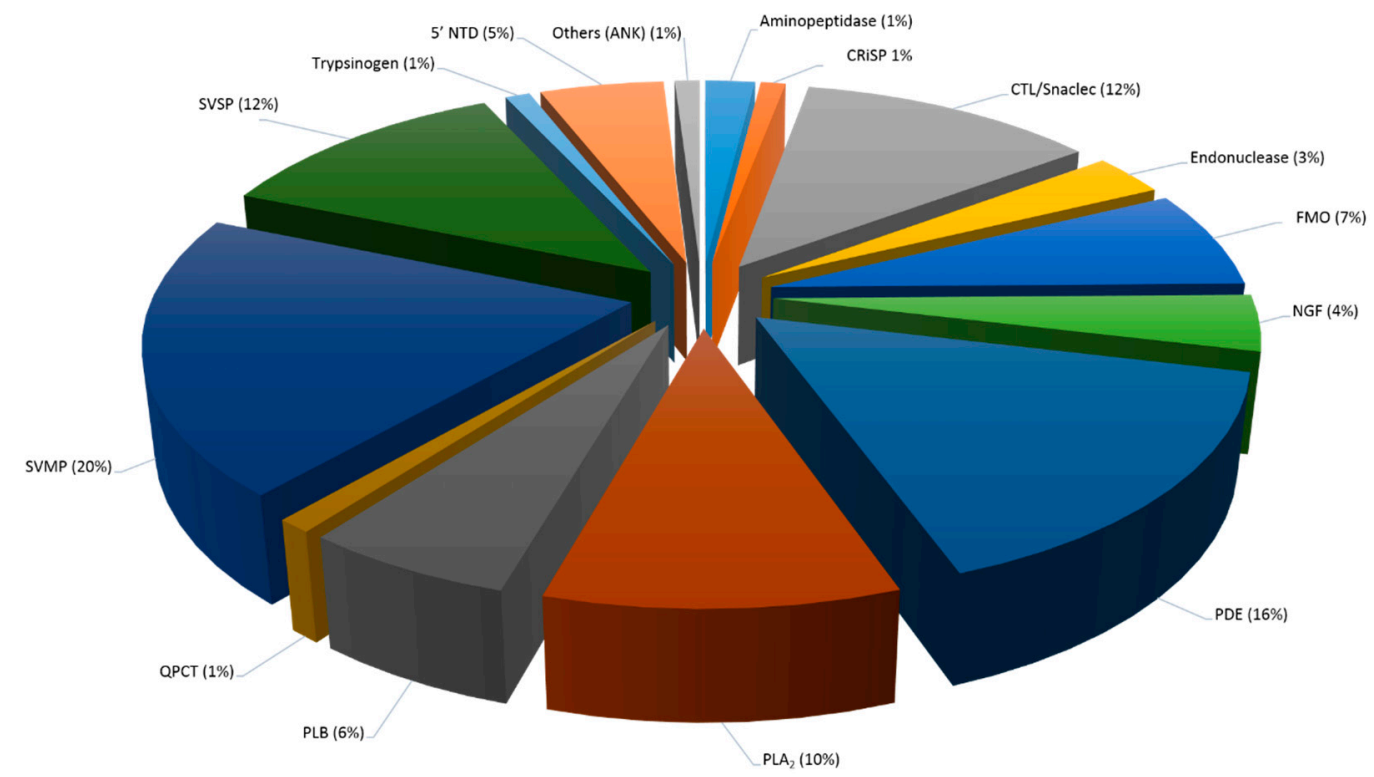

Figure 5. The proteome of Malaysian Calloselasma rhodostoma venom. Pie chart represents the relative abundance (expressed in percentage) of protein families identified in the whole crude venom. A total of 15 toxin families were determined by a combination of nanoflow liquid chromatography coupled with electrospray tandem mass spectrometry (ESI-LC-MS/MS) and automated de novo sequencing. Abbreviations: CRiSP: Cysteine-rich secretory proteins; CTL: C-type lectin; FMO: Flavin monoamine oxidase; NGF: Nerve-growth factor; PDE: Phosphodiesterase; PLA 2 : Phospholipase $A_{2} ;$ PLB: Phospholipase B; QPCT: Glutaminyl-peptide cyclotransferase; SVMP: Snake venom metalloproteinase; SVSP: Snake venom serine proteinase; ANK: Ankyrin repeats. 


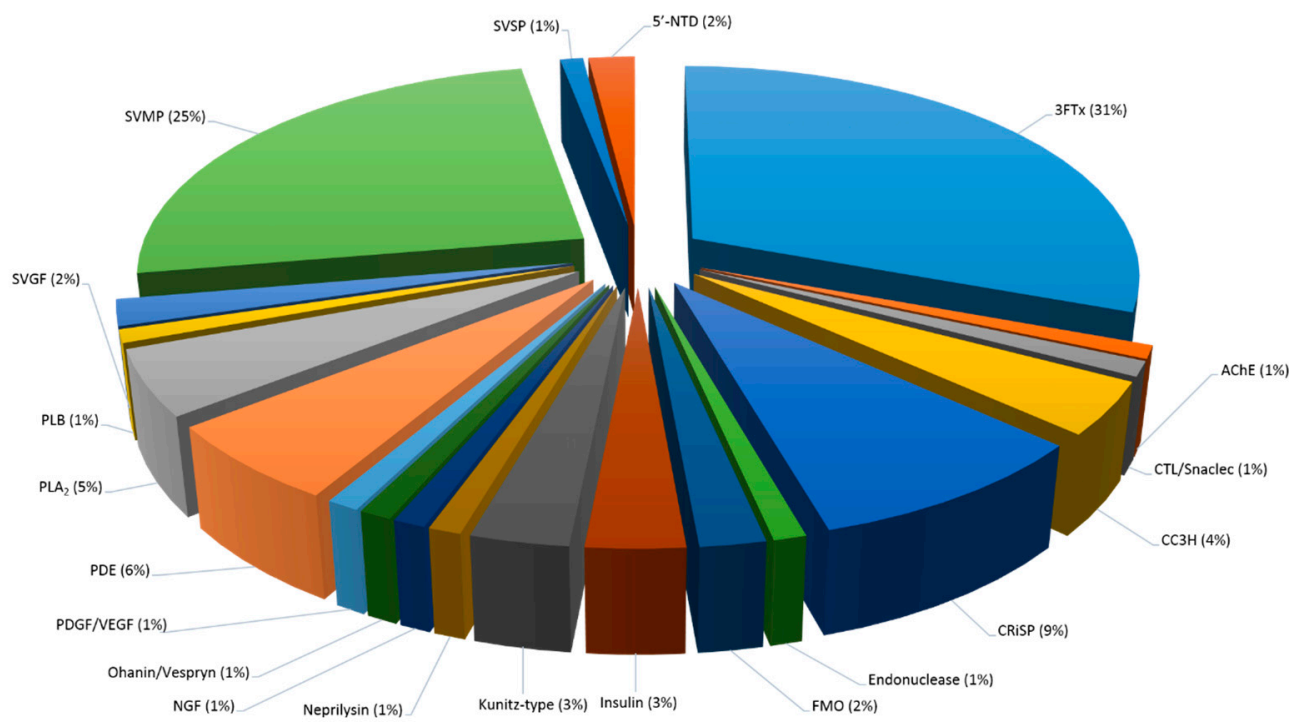

Figure 6. The proteome of Malaysian Ophiophagus hannah venom. Pie chart represents the relative abundance (expressed in percentage) of protein families identified in the whole crude venom. A total of 20 toxin families were determined by a combination of nanoflow liquid chromatography coupled with electrospray tandem mass spectrometry (ESI-LC-MS/MS) and automated de novo sequencing. Abbreviations: 3FTx: Three-finger toxins, AChE: Acetylcholinesterase; CTL: C-type lectin; CRiSP: Cysteine-rich secretory proteins; FMO: Flavin monoamine oxidase; NGF: Nerve-growth factor; PDGF/VEGF: Platelet-derived growth factor/vascular endothelial growth factor; PDE: Phosphodiesterase; $\mathrm{PLA}_{2}$ : Phospholipase $\mathrm{A}_{2}$; PLB: Phospholipase B; QPCT: Glutaminyl-peptide cyclotransferase; SVGF: Snake venom-growth factor; SVMP: Snake venom metalloproteinase; SVSP: Snake venom serine protease.

We were also interested in the identification of low abundant proteins that could be of biological interest as a potential source of active compounds or play an important role in snake envenoming. Thus, the shotgun approach was employed to target potentially indiscernible small molecular weight proteins, even by SDS-PAGE [27]. Looking at the migration and strong intensity of the protein bands in the lower molecular weight range (Figure 1), we believe that the shotgun approach provided the necessary complementary analysis. Thus, combined, the results of both techniques have facilitated a detailed proteomic view of the entire venom components (Table 5, Figures 5 and 6).

\subsubsection{Snake Venom Protein Classes in Both C. rhodostoma and O. hannah Venoms}

Generally, there are some protein families that are commonly present in the venoms of all snake families, i.e., Viperidae, Atractaspididae; Elapidae, and Colubridae, while others are restricted to certain families [28]. For instance, viper venoms usually induce hemorrhagic, hypotensive, and inflammatory effects due to high concentrations of metalloproteases, serine proteases, and C-type lectins, whereas elapid venoms usually induce neurotoxic symptoms owing to large amounts of pre- or post-synaptic neurotoxins. While these venoms may display different venom presentations, we identified a total of 11 families that were shared between these two snake families (Table 5, Figures 5 and 6). The toxin families between the two snakes are compared and discussed below.

\section{SVMP}

This class of proteins represents a major toxin family in viper venoms, including Vipernaes and Crotalinaes. In Elapidaes, the proteins make up smaller proportions of the venom. The snake venom metalloproteinases (SVMPs) are known to display a wide range of physiological activates, such as hemorrhagic, fibrinolytic, prothrombin activating, blood coagulation factor $\mathrm{X}$ activating, apoptotic, platelet aggregation inhibition, proinflammatory, and inactivation of blood serine proteinase 
inhibitors [29]. Based on their molecular weight differences and domain structure, the SVMPs are divided into three main classes: P-I, P-II, and P-III. Comparatively, P-I SVMPs are relatively small at 20-30 kDa and contain a single catalytic metalloproteinase (MP) domain. P-II SVMPs, with molecular weight between 30-60 kDa, consist of an MP domain and an additional disintegrin domain. P-III proteins are the largest at $60-100 \mathrm{kDa}$, composed of both the MP and disintegrin domains as well as a cysteine-rich domain. In general, the P-IIIs are considered the most potent of SVMPs, followed by the P-IIs and the least hemorrhagic P-Is. Interestingly, all classes of SVMPs are responsible for the classic Viperid envenoming effect, which is the ability to cause hemorrhage at the bite site [30,31]. Paradoxically, novel human therapeutics may be achieved from the bioactive peptides of SVMPs because of their haemorrhage, coagulopathy, and inflammatory responses. Several examples of SVMPs with clinical utility include Alfimeprase (A. contortrix contortrix), Integrelin (S. miliarius barbouri), Aggrastat (E. carinatus), and NN-PF3 (N. naja) [6]. In this study, we report 20\% SVMPs for the venom of the viperid C. rhodostoma and 25\% for the venom of the elapid O. hannah (Table 5, Figures 5 and 6). Although the results appear contrasting, previous studies have shown significant amount of SVMPS in O. hannah with 12\% (Balinese specimen) and 24\% (Malaysian specimen) [22,23]. However, it is important to note that despite the high amounts of SVMP detected, it is not the primary toxin family identified in the Elapidae venom. In contrast, even though only 20\% were detected in C. rhodostoma venom, this was the largest toxin family represented in this Viperidae venom.

SVSP

Our study revealed a distinct difference in the abundance of snake venom serine proteinases (SVSPs) identified in C. rhodostoma venom (12\%) compared to O. hannah venom (1\%) (Table 5, Figures 5 and 6). This is not unexpected, as SVSPs are commonly found in viperid venoms, but only in relatively low amounts in some Elapid venoms [32]. Together with SVMPs, the SVSPs are proteolytic enzymes that play important roles during snake envenoming. This family of proteins is known to exert hemostatic effects on prey by acting on various components of the coagulation cascade, on the fibrinolytic and kallikrein-kinin systems and cells to produce an imbalance of their systems [33,34]. The SVSPs that have been biologically characterized have both, or either, fibrinogenolytic and fibrinolytic activities and based on that, they either promote or inhibit coagulation. Some SVSPs are also known as 'thrombin-like' enzymes or abbreviated to SVTLE (snake venom thrombin like enzymes) due to their ability to mimic the fibrinogenolytic activities of thrombin [35]. Thrombin-like enzymes, ancrod and ancrod-2, were discovered in C. rhodostoma venom in high abundance using both shotgun and gel-filtration methods. First purified in 1967, ancrod was described as a potential anticoagulant and thoroughly researched for many years due to its potential clinical utility [36]. In O. hannah venom, only two SVSPs were identified, Alpha and beta fibrinogenase OhS1 and Neuroendocrine convertase 1. The Alpha and beta fibrinogenase OhS1 was also identified by Tan (2015) in the Malaysian king cobra species and is purported to possess potent fibrinogenolytic and amidolytic activities without any haemorrhagic consequences. In venomous animals, the neuroendocrine convertase 1 protein has only been identified in spider and gila monster venoms and the transcript of cone snail venom-glands [37-40]. The function of this protein is to convert inactive proteins into bioactive components by cleaving after Lys-Arg or after a tetrabasic sequence (Arg-X-Arg/Lys-Arg) [41,42]. Findings postulate that 'venom proprotein convertase' is most likely involved in the activation of exendins in gila monster, protoxins in spider venom, and conotoxins in cone snails (cleavage after dibasic residues) $[38,43]$. It is suggested that proforms of peptide toxins are activated by proteolytic cleavage by venom proprotein convertase, such as neuroendocrine 1 [37].

\section{CRiSP}

Cysteine-rich secretory proteins (CRiSPs) are relatively small glycoproteins (molecular weight 20 to $30 \mathrm{kDa}$ ) with a high degree of amino acid sequence similarity and highly conserved specific pattern of 16 cysteine residues [44-46]. This family of proteins are widely distributed and have been established 
in mammals, Drosophila, Xenopus, Heloderma horridum horridum, Caenorhabditis elegans, and Conus textile. Some of their proposed biological functions are gamete fusion, sperm maturation, anti-microbial and matrix-degradation, sperm chemoattractant, $\mathrm{Ca}^{2+}$ and $\mathrm{K}^{+}$channel blockers, longevity and stress resistance regulators, and protease-like activity [44]. In snakes, they are found in most families, including Viperidae, Elipidae, and Colubridaes, demonstrating $\mathrm{Ca}^{2+}$ channel blocker-like properties and cyclic nucleotide-gated channel blocker activities $[47,48]$. This study revealed 15 CRiSP proteins in O. hannah venom (9\%), but only one CRiSP protein in C. rhodostoma venom (1\%) (Table 5, Figures 5 and 6). This finding coincides with previous studies, whereby individual acidic and basic fragments of the same protein were identified. The 15 CRiSPs in 0 . hannah venom showed sequence similarities to 12 different species (Tables 2 and 4). The ophanin from O. hannah venom was first purified and characterized in 2003 and compared to nine other snake venom CRiSP proteins. Based on the phylogenetic tree constructed in that study, it was suggested that $O$. hannah is more closely related to the Viperidae snakes rather than Elapidae snakes owing to the similarity of the nucleotide sequence of ophanin with the Viperidae snakes [49].

Phospholipase $\mathrm{A}_{2}$

Phospholipase $\mathrm{A}_{2}$ 's activates the hydrolysis of glycerophospholipids at the sn-2 position of the glycerol backbone to dissociate fatty acids and corresponding 1-acyl lysophospholipids [2,50]. Over the years, the toxic and pharmacological effects presented by these enzymes have been well-documented. Effects include neurotoxic, myotoxic, cardiotoxic, cytotoxic, hemolytic, hypotensive, platelet aggregation, anticoagulant, pro-inflammatory, edematogenic, and bactericidal activities [50,51]. Widespread in nature, $\mathrm{PLA}_{2}$ has been identified in venoms from all snake families; i.e., Colubridae, Elapidae, Viperidae, and Hydrophilae [32]. Here, we report relatively high amounts of PLA 2 enzymes in both C. rhodostoma and O. hannah venoms with 10\% and 5\%, respectively (Table 5, Figures 5 and 6). The number of identified PLA 2 peptides in this study is noticeably higher than reported in previous studies [19-22,52,53]. Ali et al. (2013), Vejayan et al. (2014), and Tsai et al. (2001) reported the presence of both acidic and basic isoforms of $\mathrm{PLA}_{2}$ in C. rhodotoma venom, whereas Tang et al. (2016) primarily identified the basic form of the enzyme. Additionally, Tang et al. identified two PLA 2 peptides in minute amounts with sequence similarity to $N$. kaouthia venom, one of which was an acidic fraction found in less than $0.01 \%$ abundance. In our study, we identified a total of $11 \mathrm{PLA}_{2}$ peptides (both acidic and basic isoforms), discovering more than two times the number of $\mathrm{PLA}_{2}$ compared to the latest proteomic analysis [19]. PLA 2 peptides from C. rhodostoma venom had similar sequences to PLA 2 peptides from O. hannah, T. stejnegeri, C. atrox, T. sabahi, and C. horridus venoms. Tsai et al. and Tan et al. both reported that the major PLA 2 isolated from the Malaysian king cobra is the acidic isoform of the enzyme [22,52]. Based on the protein score obtained in our study, we are in agreement with their findings. The additional $\mathrm{PLA}_{2}$ peptides from $O$. hannah venom showed similarity to sequences from C. rhodostoma, B. fasciatus, M. fulvius, and T. biscutatus venoms. However, the higher number of PLA $2 \mathrm{~S}$ identified for both venoms here provides evidence that intragenic variations may indeed be influenced by ontogenic factors as suggested by Tan et al. (2015), which in turn will have significant impacts on the outcome of snake envenoming in Malaysia.

\section{PLB}

Phospholipase type B (PLB) is another member of the phospholipase superfamily. However, compared to $\mathrm{PLA}_{2}$, information on this enzyme is relatively scarce. The lack of data could be due to the limited identification of this enzyme in snake venomics analyses and/or the minute amounts of the enzyme that have been detected in snake venoms [54]. PLB hydrolyzes monoacyl phosphatides by liberating free fatty acid and forming glycerophosphoryl derivatives. To date, phospholipase B activity has been reported in snakes by Doery and Pearson (1964), Van Deenen and Haas (1963), Mohamed (1969), Shiloah (1973), and Bernheimer (1987) [55-59]. One study presented hemolytic and cytotoxic activities in Pseudechis colletti venom, indicating possible biological effects of this enzyme. In mice, PLB 
causes myoglobinuria, a muscle destruction occurrence also exerted by PLA 2 . Interestingly, Shiloah (1973) also observed that purified N. naja PLA 2 isoforms presented PLB activity at specific experimental conditions. This finding led to the suggestion that PLB activity found in snake venoms may be due to a dual action by $\mathrm{PLA}_{2}$ [5]. In this study, we discovered 6\% of PLB peptides in C. rhodostoma venom and $1 \%$ in $O$. hannah venom (Table 5, Figures 5 and 6). A previous proteome study for the Malaysian C. rhodostoma venom reported less than $1 \%$ of this enzyme, whereas the Malaysian O. hannah venom presented only one PLB peptide, which is in accord with our study. Although, PLB identification and quantification has been limited thus far, Tan (2015) reported that the enzyme is present in some vipers and pit vipers [54,60-62]. In a recent proteomic study by Zainal Abidin et al. (2017) this finding was confirmed with a total of $8 \%$ and $2 \%$ of PLB enzymes reported for Malaysian T. wagleri and C. purpureomaculatus vipers, respectively. Although the exact pathophysiological role of PLB in venom has not been elucidated, the recent increasing abundance discovered in viper venoms may suggest a more significant role in snake envenoming than first predicted.

\section{$\mathrm{CTL} /$ snaclec}

Classically, CTLs bind to calcium and sugar residues (hence, " $\mathrm{C}$ " calcium and lectin). However, the C-type lectin-like proteins of snake venom do not contain the calcium and sugar binding loop and, thus, do not have lectin activity $[63,64]$. To avoid confusion between classic C-type lectins and C-type lectin-like proteins, the latter was termed snaclec (snake venom c-type lectins). Snaclecs exhibit numerous biological activities, including anticoagulation, pro-coagulation, and platelet modulating (agonist and antagonist) activities [63]. The phenomenon of contrasting platelet activity in snake venom has been reported in several crotalids, such as H. hypnale, D. acutus, and C. rhodostoma species $[19,65,66]$. Nevertheless, CTLs and snaclecs are considered to be abundant components of snake venom, particularly in vipers. In elapids, only minor amounts $(<2 \%)$ have been reported in about one third of the family. Here, we report the abundance of CTL/snaclecs in C. rhodostoma with $12 \%$ compared to $1 \%$ in O. hannah venom (Table 5, Figures 5 and 6). In C. rhodostoma venom, we identified all four subunits of rhodocetin, the platelet aggregation inhibitor snaclec. We also identified both alpha and beta subunits of rhodocytin, the platelet aggregation inducer snaclec that was previously known as aggretin and rhodoaggretin. Previous studies have shown evidence of these proteins grouped as one of the major components in C. rhodostoma venom [19,21]. In contrast, Tan et al. (2015) reported that although CTL venom-gland transcripts from the Malaysian and Balinese O. hannah venom were discovered, the transcribed genes were not translated into proteins. In this study, we present the first report of snaclec proteins found in O. hannah venom. The two CTL/snaclec peptides discovered in O. hannah venom showed sequence similarity to the alpha and beta subunits of the platelet aggregation inhibitor, rhodocetin, from C. rhodostoma venom.

\section{FMO (L-amino Acid Oxidase)}

L-amino acid oxidases (LAAOs) belong to the flavin monoamine oxidase (FMO) family and are considered one of the best studied protein families from snake venom. Since the discovery of snake venom LAAOs, many reports have been published on various species of the enzyme. Generally known as flavoenzymes, LAAO catalyzes the stereospecific oxidative deamination of an L-amino acid substrate to produce an $\alpha$-ketoacid equivalent as well as ammonia and hydrogen peroxide [67-69]. Although the pathophysiological role in snake venom has not been defined, researchers have taken advantage of this well-characterized enzyme to study the biological and pharmacological activities of LAAOs. Some of the reported biological effects include hemorrhage, edema, coagulation, and platelet aggregation, whereas pharmacological effects include antimicrobial (virus, bacteria, and parasite) and anti-cancer activities [70]. In a recent snake venom database review, it was reported that $91 \%$ of all crotalinae species contained LAAO enzymes and the maximum amount identified thus far is from the crotalinae $R$. cotiara, constituting $20 \%$ of the venom. Although important in elapidaes and viperinaes, the enzymes only make up approximately $6 \%$ of their venoms [32]. In the current study, we report 
$7 \%$ LAAOs in C. rhodostoma venom and $2 \%$ in O. hannah venom (Table 5, Figures 5 and 6). Although, the relative abundance reported here seems to be much lesser than reported by Ponnudurai et al. (1994), this value is in agreement with Tang et al. (2016), who reported a little less than $7 \%$ of LAAO in C. rhodostoma venom [71]. The study suggested that the discrepancy between the reported quantities is probably due to the lack of sensitivity in detecting other proteins in the whole venom. As for O. hannah venom, Tan et al. (2015) reported approximately $6 \%$ of LAAO from only two peptides [22], which is the same number of peptides detected in the current study. The difference in abundance is probably due to different quantitative analyses employed to determine the relative abundance. The sequence similarity of O. hannah LAAO peptides detected was observed in C. rhodostoma and O. hannah venoms, and the similarity with C. rhodostoma LAAO peptides was seen in C. rhodostoma, B. schelegelii, T. stejnegeri, L. muta, and B. fasciatus venoms. Several amine oxidase peptides were also observed in both venoms, with three peptides found in C. rhodostoma venom and one peptide in O. hannah venom.

\section{NGF}

This proteome analysis revealed $4 \%$ and $1 \%$ of nerve growth factors (NGFs) in C. rhodostoma and O. hannah venoms, respectively (Table 5, Figures 5 and 6). In C. rhodostoma venom, a total of four peptides were discovered showing sequence similarity to venoms from B. jararacussu, P. flavoviridis, and B. atrox, whereas two peptides were found in $O$. hannah venom, with similarity to venoms from $W$. aegyptia and $O$. hannah. Snake venom nerve growth factors were first discovered serendipitously by Cohen and Levi-Montalcini [72]. In an effort to break down the nucleic acid portion of a purified component from a growth promoting secretion, Agkistrodon piscivorus venom was shown to be a significant inducer of nerve growth [72,73]. Since its discovery, numerous snake venom nerve growth factors have been purified and characterized from various snake venoms [74]. Reports have revealed that sv-NGFs are approximately 13 to $35 \mathrm{kDa}$, consisting of 10 to $20 \%$ of carbohydrates and are of great therapeutic interest for the treatment of neurodegenerative disease [75]. Apart from its growth promoting activity, sv-NGF has been proposed to possess vasculotoxin-like behavior, potentially to render the venom injection site more susceptible to facilitate infiltration of venom components into target tissues [76]. While sv-NGF has been established in Viperidae, Crotalinae, and Elapidae families, it is shown to occur in minute amounts (i.e., $0.1-0.5 \%$ ) in several snake venoms [76,77]. Our findings here show a relatively higher amount than previously reported for both venoms $[19,22]$.

\section{PDE}

Although PDEs are considered ubiquitously present in snake venoms, reports have described lower levels of PDE activity in elapids compared to crotalids and viperids [78]. In accordance, our analysis revealed $16 \%$ and $6 \%$ of phosphodiesterase (PDE) proteins in C. rhodostoma and O. hannah venoms, respectively (Table 5, Figures 5 and 6). This class of toxins, also termed exonucleases, catalyzes the hydrolysis of phosphodiester bonds to release $5^{\prime}$-mononucleotides from the $3^{\prime}$ end of polynucleotides to provide nucleotide substrates to facilitate the activity of other toxins, such as 5'-nucleotidases [5,78]. In 1963, Russell et al. observed mean arterial pressure reduction and locomotor depression using PDE fractions from several snake venoms. Apart from this evidence of their potential function and as well as their hydrolytic properties, there is little information on the other pharmacological activities of these toxins [79]. The PDE peptides identified from C. rhodostoma venom showed similarity to peptides from C. adamateus, C. horridus, and S. miliarius barbouri venoms (Tables 1 and 3). Likewise, O. hannah PDE peptides displayed similarity to C. adamanteus and C. horridus, as well as O. okinavensis, M. fulvius, and M. tener PDE peptides (Tables 2 and 4). Interestingly, only minor amounts of PDEs were observed in the other proteomic analysis of King cobra and Malayan pit viper venoms $[19,22,23,80]$. 


\section{Endonuclease}

It is important to clarify that denominating endonucleases from nucleases has been a somewhat ambiguous endeavor. This is because endonucleolytic activity is an inherent property of venom PDEs (exonucleases). Endonucleases are made up of DNases that hydrolyze DNA, as well as RNases that hydrolyze RNA. Whereas, exonucleases are made up of PDEs that have the ability to hydrolyze both DNA and RNA [81]. To facilitate differentiation, parameters, such as the $\mathrm{pH}$ optima and metal ion requirement, were considered. To date, although this approach has provided some clarity, describing exclusive nuclease (endo and exo) activity is still considered a challenge. In our study, endonucleases were categorized from both venoms. Albeit in fairly low amounts, there was 3\% in C. rhodostoma venom and $1 \%$ in $O$. hannah venom (Table 5, Figures 5 and 6). Two peptides showing sequence similarity with $O$. hannah venom were discovered for both venoms, with an additional DNase-like protein showing sequence similarity with $C$. adamanteus found for C. rhodostoma venom (Tables 2-4). Thus far, no endonuclease proteins have been identified for these Malaysian specimens.

\section{Nucleotidase}

$5^{\prime}$-Nucleotidase (5'-NTD) are high molecular weight glycoproteins and metalloenzymes ranging from $70 \mathrm{kDa}$ to $100 \mathrm{kDa}$ [77,79]. Primarily, 5'-NTDs endogenously liberates purines by selectively hydrolyzing $5^{\prime}$-nucleotidase to nucleosides $[78,82]$. Recent studies have indicated that $5^{\prime}$-NTDs play a crucial role in snake envenoming strategies of prey immobilization (via hypotension and paralysis) and prey digestion. This is because purine is the central component in all these strategies, whereby injection of exogenous nucleosides via venom and release of endogenous nucleosides via prey tissue, exert synchronous effects to bring about death. Thus, the ability of $5^{\prime}$-NTDs to provide a steady supply of purines has labelled them a multitoxin [79]. Though their biological functions have not been exhaustively studied, these enzymes are responsible for anticoagulant effects and inhibition of platelet aggregation in several snake venoms [83-86]. While ubiquitously distributed in snake venoms, $5^{\prime}$-NTD activity is more prominent in viperid venoms than elapid venoms. Our study reports $5 \%$ of $5^{\prime}$-NTDs in viperid C. rhodostoma venom and $2 \%$ in elapid O. hannah venom (Table 5, Figures 5 and 6). Interestingly, the $5^{\prime}$-NTDs found in O. hannah venom were mainly ecto-nucleotidases showing sequence similarity to $M$. tener and M. fulvius (Table 2). Ecto-enzymes, such as ecto-5'-nucleotidases, are essentially membrane-embedded enzymes, with their active sites positioned on the exterior surface of the cell [78].

\subsubsection{Snake Venom Protein Classes in C. rhodostoma Venom}

In our study, we have shown that $O$. hannah venom contains a relatively high abundance of disintegrins (SVMP) and minor amounts of CTLs, protein components that occur in almost all viper venoms. However, there were several protein families that were detected exclusively in the viper, C. rhodostoma venom, albeit in low abundance. These toxin families are described in the following section.

Low Abundance Proteins Only $(<2 \%)$

A total of three protein families with relative abundance of less than $2 \%$ each were discovered in C. rhodostoma venom. These proteins were from the aminopeptidase, glutaminyl-peptide cyclotransferase (QPCT), and Ankyrin (ANK; designated as 'Others') families (Table 5, Figure 5). The aminopeptidase protein family is considered one of several less well understood enzyme constituents of snake venom. Reports of aminopeptidase activity have been presented in elapidae and viperidae crude venoms as well as a crotalinae venom fraction [28]. However, although there has been evidence of aminopeptidase transcripts in several species of snake venom glands, aminopeptidase proteins have only been identified in three snake venom proteome studies $[25,87,88]$. Here, we report the proteomic identification of aminopeptidase peptides in the venom of crotalinae, C. rhodostoma for the first time (Table 3). The two identified peptides sequences showed similarity to the aminopeptidase 
sequence from $C$. horridus venom. Thus far, the role of aminopeptidases in snake venom has not been fully elucidated. However, analogous comparisons have been made with mammalian aminopeptidases, proposing their importance in regulating brain function and blood pressure [28,89]. Further suggestions include disrupting physiological processes though cleavage of oligopeptide N-terminals, degradation of host tissues, increasing permeability to venom components, or processing toxins components within the venom [28].

One glutaminyl-peptide cyclotransferase (QPCT) was detected in the C. rhodostoma proteome, constituting only $1 \%$ of the entire crude venom (Table 5, Figure 5). The peptide identified for this protein showed sequence similarity to QPCTs from the venom of another crotalinae, $A$. contortrix contortrix (Table 3). Remarkably, glutaminyl cyclases were found to be notably present in crotalines, but not viperine venoms. Studies that have identified this protein in snake venom proteomes include other crotalinaes, C. durissus terrifcus, C. atrox, and C. purpureomaculatus [32]. Interestingly, Zainal Abidin et al. (2016) reported the absence of this protein in another crotalinae, T. wagleri. However, the proteome of T. wagleri was reported to be somewhat atypical compared to other viperid species [32,62]. Additionally, transcripts have been reported in the venom glands of more crotalinaes, S. catenus edwardsii and B. jararaca [90-93]. QPCTs are considered to be another poorly understood protein component in snake venoms. Very few QPCTs have been purified or isolated and therefore not thoroughly evaluated [94]. Nevertheless, it has been suggested that QPCTs play a role in post-translational modification (PTM), whereby they catalyze the N-terminal pyroglutamate (pGlu) portion of toxins to release ammonia or water molecules. Atypical to toxins, QPCTs may be involved in toxin maturation, protection from exopeptidase degradation, and aiding accurate protein conformation [95].

One of the low abundance peptides identified in C. rhodostoma venom identified an unusual protein domain designated as Ankyrin repeat-containing protein showing sequence similarity to A. contortrix contortrix venom (Table 1, Figure 5). Interestingly, the Ankyrin protein was initially described as a 33 amino acid repeat found amongst a few proteins in Drosophila melanogaster, a common fruit fly. Later, it was termed a cytoskeletal protein that was made up almost entirely of these short repeats [96]. Since then, the Ankyrin (ANK) repeats have been found to occur in thousands of proteins in viruses, prokaryotes, and eukaryotes. No particular function has been attributed to the ANK repeats, however, there are suggestions of their involvement in mediating protein-protein interactions [97]. In venomous animals, the most prominent work on Ankyrin repeats has been reported in a black widow spider, Latrodectus tredecimguttatus, transcriptomics study. The Ankyrin repeats were grouped as a superfamily consisting of five subfamilies (mainly $\alpha$-latrotoxins), which differed in the number and distribution of ANK domains present in individual toxin families. As the ANK repeats were predominantly abundant in the main neurotoxic proteins identified in the venom, ANKs were included as part of the neurotoxin family [98]. However, looking at the low protein score (Table S1) coupled with the identification of only a single ANK peptide, we believe that the protein does not play a significant role in the venom and may serve in other general non-toxic functions.

\subsubsection{Snake Venom Protein Classes in O. hannah Venom}

One of the key differences between C. rhodostoma venom and O. hannah venom was the absence of 3FTx in the viper venom. This toxin family was identified as the most abundant protein family in the elapid venom. Other major protein families that were found exclusively in $O$. hannah venom were complement C3 homolog, Kunitz-type, and insulin, while several other low abundance families were also discovered in the venom, notably SVGF, hepatocyte growth factor (Table 5). The nine protein families only present in O. hannah venom are discussed below.

\section{FTx}

Three-finger toxins (3FTx) are a class of proteins that belong to the snake venom superfamily, with a conserved three finger like appearance in three dimensional structures. 3FTx are commonly found in venoms of elapid snakes and are known to be a major contributing lethal factor to Elapidae 
and also Hydrophidae venoms [99-101]. As expected, we found a total of 55 proteins (31\%) belonging to this family from the Malaysian $O$. hannah venom, but not $C$. rhodostoma venom (Table 5, Figure 6). The majority of the 3FTxs detected belonged to the long-chain subfamily $(65 \%)$, whereas the rest were appropriated to the short-chain and non-conventional subfamilies. All identified peptides showed similar sequences to Elapidae venoms; N. kaouthia, N. oxiana, N. annulata annulata, N. haje haje, N. nivea, N. melanoleuca, N. naja, N. sputatrix, D. polylepis polylepis, D. viridis, B. multicinctus, B. flaviceps, A. superbus, and A. labialis (Tables 2 and 4). Interestingly, there was a sequence similarity detected with a Viperidae venom, $C$. rhombeatus, of a short chain 3FTx, neurotoxin-like protein 1 . Evolution has allowed snakes to adapt to a variety of prey and although previously thought to be unique to elapidaes, studies have shown the presence of elapidae components across snake families, including a non-venomous C. radiatus gland secretion [102].

\section{Complement C3 Homolog}

The complement C3 homolog family consists of proteins interacting with components of the serum complement system that modulate the immune system. In venom, this group is a structural and functional analog of complement component $\mathrm{C} 3 \mathrm{~b}$, the activated form of $\mathrm{C} 3$. The cobra venom factor (CVF) is one of the best studied proteins in this family [103]. It is a glycoprotein, $150 \mathrm{kDa}$ and is frequently composed of alpha, beta, and gamma chains. When introduced into the bloodstream, it stimulates complement activation and results in the consumption of the complement activity. The CVF protein is known to be specific to the cobra species of the Elapidae family. Although the function of the purified CVF has been demonstrated in vivo, the exact biological role of CVF in cobra venom is still not fully understood $[103,104]$. In our findings, we have categorized seven proteins $(4 \%)$ in this family consisting of complement-depleting factor, Ophiophagus venom factor, and venom factors (Tables 2 and 4, Figure 6). Despite being annotated as a venom factor of a cobra, the purified protein is known to be non-toxic [103].

Kunitz-Type

Kunitz-type is a family of toxins consisting of a Kunitz domain with a serine protease inhibiting function. The characteristic domains are made up of a conserved fold of about 60 amino acids and three disulfide bridges. The family is also known as the bovine pancreatic trypsin inhibitor (BPTI) and is naturally present across the animal taxa $[105,106]$. Similar to 3FTx, this toxin family has evolved due to gene duplication and positive selection. Originally, the role of Kunitz type toxins was to inhibit the function of serine protease, but, over the years, some have evolved to block ion channels, such as $\mathrm{K}^{+}$ and $\mathrm{Ca}^{2+}$. However, a few of these toxins have the novel ability of reserving their protease inhibitory function as well as ion channel modulatory function, and therefore acquiring a bifunctional status [107]. Here, we have identified six 'original' Kunitz-type proteins appearing to have retained their protease inhibitory function. The Kunitz-type protein made up 3\% of the total venom (Tables 2, 4 and 5, Figure 6). Although previous studies have isolated these serine protease inhibitors from Elapidae and Viperidae venoms [108], there were no peptides that matched the identity of a Kunitz-type protein for Malaysian C. rhodostoma venom.

Insulin

Over the years, the advancement of investigational techniques in protein chemistry have propelled the recognition of insulin as being a part of a large protein superfamily that is present in various types of organisms. This superfamily consists of insulin and related peptides, such as insulin-like peptides and insulin-like growth factors as well as relaxins [109]. One very exciting discovery is the first example of insulin in a venom and furthermore an invertebrate of a cone snail, Conus geographus [110]. In snake venom, particularly $O$. hannah, there has been evidence at the transcriptional level of venom glands [22,23] and proteomic level [80]. However, due to the lack of evidence in other snake venoms, the transcriptomic findings were classified as rare and thus, in need of more thorough or detailed 
investigation. Here, we would like to document the presence of five insulin-like growth factor 1 proteins identified for the first time at the proteomic level of Malaysian O. hannah venom, making up $3 \%$ of the total venom (Tables 2 and 4, Figure 6). Previously, the lack of identification at the proteomic level was attributed to extremely minute amounts of proteins in the venom. Therefore, we believe that our discovery is noteworthy as almost all except one protein was identified through the concentrated molecular weight separation fractions compared to the crude shotgun method.

Low Abundant Proteins in O. hannah Venom $(<2 \%)$

Snake venom acetylcholinesterase (AChE) was first reported in 1938 when strong choline esterase activity was observed in three cobra species. Together with butyrylcholinesterase (BuChE), AChE makes up the snake venom cholinesterase family and functions to hydrolyze choline esters [111]. Studies have shown that Bungarus fasciatus venom contains high concentrations of AChE at approximately $8 \mathrm{mg} / \mathrm{g}$ of dry venom with strong activity reported at around 750,000 Ellman units/mg, designating this venom as the richest source of this enzyme. Interestingly, AChE activity has only been demonstrated in Elapidae venoms, but not in Viperidae or Crotalidae venoms [112]. Not surprisingly, we detected only two peptides belonging to the AChE family, one showing sequence similarity with B. fasciatus and the other a carboxylic ester hydrolase from S. fasciata (Tables 2 and 4). No AChE peptides were recovered from $C$. rhodostoma venom. Neprilysin is a zinc-metalloendopeptidase with specificity to the bacterial zinc peptidase, thermolysin. Originally located in the rabbit kidney, the first observation of the protein in snake was in the form of a transcript in the saw scaled viper venom of E. pyramidum leakeyi $[113,114]$. Other neprilysin transcripts were reported in the Balinese and Malaysian king cobra. The latter study also reported the first proteomic evidence of neprilysin in Malaysian O. hannah venom [22]. In this study, we report the presence of one neprilysin (Table 2) compared to two identified by the other Malaysian sample. In mammals, neprilysin has been implicated in neuropeptide regulation, however, its role in venom has not been elucidated [115].

Another low abundant, but noteworthy, toxin family in O. hannah venom is the Ohanin/Vespryn family. This family is a relatively new family of snake venom proteins established in 2005. Ohanin, a novel protein with unusual molecular mass, was isolated from King cobra venom that displayed an uncharacteristically low content of cysteine residues (1\%). Comparison of amino acid sequence revealed a $93 \%$ sequence similarity with Thai cobrin, an isoform from the monocled cobra, Naja kaouthia. However, to date, there is no literature available on Thai cobrin [116]. The proteins possess the PRY and SPRY domain (B30.2-like domain) sequences that are the trademark for vespryn proteins, but do not share sequence similarity to other proteins in the snake venom database. This feature, coupled with the low cysteine residue content, makes both proteins exclusive members of this toxin family. Ohanin has been synthesized as a precursor named prohanin, with a propeptide segment at the C-terminal segment that completes the SPRY domain [117]. Prohanin (THA 903) has shown strong pharmacological potential and is currently undergoing clinical trials for the treatment of chronic pain [118]. In this study, we identified ohanin from $O$. hannah venom and its isoform, Thaicobrin, from the $N$. kaouthia venom (Tables 2 and 4), revealing a total of $1 \%$ of this protein family in the overall venom composition (Table 4, Figure 6).

The proteomic analysis of Malaysian king cobra in this study also discovered single peptides of snake venom growth factors (SVGFs): Hepatocyte-growth factor activator, macrophages colonystimulating factor (MCSF), tumor necrosis factor receptor (grouped as SVGF), and one other peptide, PDGF/VEGF growth factor (Tables 2 and 4, Figure 6). Historically, growth factors represent growth and cell proliferation. Since then, the attributes have evolved to include neutrophins, such as cell differentiation, transformation, synthesis secretions, motility, and death [119]. Over the years, hundreds of snake venom growth factors (SVGFs) have been isolated, studied, and deposited in the UniProt databank. This includes the abovementioned platelet-derived growth factor (PDGF), vascular endothelial growth factor (VEGF), tumor necrosis factor (TNF), hepatocyte growth factor-tyrosine kinase (HGF), insulin-like growth factor-binding protein (IGF), and nerve growth factor (NGF) that has 
been discussed throughout this proteomic analysis [77]. Remarkably, prior to this study, the hepatocyte growth factor activator protein was only identified at the proteomic level in Thai O. hannah [80]. The investigations of $O$. hannah species from Malaysia and Bali did not report the presence of this peptide in their proteomic analyses [21-23]. In this study, the hepatocyte growth factor protein was discovered using both proteomic approaches and constitutes approximately $1 \%$ of the entire venom (Tables 2 and 4, Figure 6). The hepatocyte growth factor is known to stimulate development and migration of vascular endothelial cells. This particular growth factor has demonstrated accelerated glomerular restoration via capillary endothelial cell growth and capillary regeneration in experimental progressive glomerulonephritis [120]. The other two growth factors (TNF and MCSF) were also not identified in the Malaysian, Thai, or Balinese specimens [21-23,80]. However, the presence of VEGF proteins was reported in the Balinese and Thai proteomes [23,80].

The focus of this study was to provide comprehensive proteomic profiles of Malaysian CR and $\mathrm{OH}$ snakes by maximally identifying the proteins present within their venom composition. We utilized venom samples from three separate pools (species) from the northern region of Malaysia, which provides a robust statistical framework for general venom composition identification. Nonetheless, further work, including a broader area of sampling around Malaysia, is necessary for a more detailed appreciation of individual differences between species.

Finally, this venomic investigation has provided evidence of major venom proteins, including SVMP, PDE, SVSP, CTL/snaclec, PLA 2 , FMO, PLB, 5'-NTD, NGF, Endonuclease, and CRiSP, as well as minor venom proteins consisting of Aminopeptidase, QPCT, Trypsinogen, and Ankyrin repeats in C. rhodostoma venom. Likewise, major protein components from 3FTx, SVMP, CRiSP, PDE, PLA 2 , Complement C3, Kunitz-type, and Insulin, along with minor components from SVGF, FMO, 5' -NTD, CTL/snaclec, SVSP, AChE, Ohanin/Vespryn, NGF, Endonuclease, Neprilysin, PDGF/VEGF, and PLB were determined in $O$. hannah venom. At this point of the study, it is difficult to distinguish if the small numbers of low abundance proteins found in the venom are indeed novel species-specific proteins or rare proteins that are yet to be discovered in other snake species. Nevertheless, the data obtained from our global proteomic analysis has revealed the presence of inherent medically and pharmacologically important components within Malaysian C. rhodostoma and O. hannah crude venoms, possessing potential clinical utility as tools or as prototypes for drug design studies.

\section{Conclusions}

Using a combination of two proteomic approaches, shotgun and gel-filtration fractionation techniques, we have provided a holistic view of the complex Malaysian C. rhodostoma and O. hannah crude venom protein compositions. As a forethought, we would like to highlight that proteins from the insulin, CTL/snaclec, and SVGFs families were identified for the first time in O. hannah venom in a proteomics study. Proteins from the Aminopeptidase, QPCT, and Ankyrin families in C. rhodostoma venom were also reported for the first time. In addition, the total number of proteins identified in both venoms is higher than reported in previous proteomic studies. Looking at the discrepancies between previous studies and our study, this finding is perhaps not exhaustive, but definitely supplementary, to previous findings and data collection. Nonetheless, we reiterate that the discovery of these new proteins will significantly impact the knowledge of the venom components in both these species, which may be used as a reference for improved antivenom production, understanding pathological effects of envenoming, and the discovery of biologically active peptides with medical and biotechnological values.

\section{Materials and Methods}

\subsection{Materials}

\subsubsection{Snake Venom}

Calloselasma rhodostoma and Ophiophagus hannah snake venoms were milked from adult snakes originating from the northern part of the west coast of Peninsular Malaysia (Perlis). Crude venoms 
were obtained from Mr. Zainuddin Ismail, a private snake enthusiast from Perlis. Manual milking was performed by placing the snake's fangs on a parafilm-covered sterile container. Extracted venom samples were transported on ice to Monash University Malaysia (Sunway Campus). The venom samples were immediately frozen at $-80{ }^{\circ} \mathrm{C}$, lyophilized via a freeze-dryer, and stored at $-20{ }^{\circ} \mathrm{C}$ until required. Quantification of the crude protein was carried out by performing a Bicinchoninic acid (BCA) assay as outlined by the manufacturer (Pierce Biotechnology, Rockford, IL, USA), using bovine serum albumin (BSA) as the standard.

\subsubsection{Columns, Drugs and Chemicals}

The Superdex G-75 (10 mm × $300 \mathrm{~mm})$ and Hi-trap G-25 $(16 \mathrm{~mm} \times 25 \mathrm{~mm})$ were purchased from GE-Healthcare (Uppsala, Sweden), whereas the Zorbax 300SB-C18 (75 $\mu \mathrm{m} \times 150 \mathrm{~mm}, 5 \mu \mathrm{m})$ was purchased from Agilent (Santa Clara, CA, USA). The chemicals and reagents used were of analytical grade, except LCMS grade materials from Fisher Scientific (Leicestershire, UK) for all LCMS work. Water used in this study was ultrapure.

\subsection{Methods}

\subsubsection{Sodium Dodedyl Sulfate-Polyacrylamide Gel Electrophoresis (SDS-PAGE)}

Protein profiles of C. rhodostoma and O. hannah crude venom samples were assessed by SDS-PAGE according to Laemmli, 1970 [121]. Electrophoresis runs were carried out under reducing conditions in $12 \%$ resolving gels and $4 \%$ stacking gels in room temperature. Fractions were boiled at $95{ }^{\circ} \mathrm{C}$ for $5 \mathrm{~min}$ and allowed to cool to room temperature before being loaded onto the gel and run for approximately $60 \mathrm{~min}$ at $200 \mathrm{~V}$ in $1 \times$ SDS running buffer. The gels were fixed for $10 \mathrm{~min}$ in fixing solution and visualized through staining with Coomassie Blue R-350 (1 h or overnight) and de-staining with Coomassie de-stain (overnight). The molecular weights of protein bands were estimated using broad range SDS-PAGE molecular weight standards from Thermo Scientific (Rockford, AZ, USA).

\subsubsection{In-solution Protein Digestion}

Crude venom solutions (Section 4.2.3) and gel-filtration protein fractions (Section 4.2.4) were prepared for identification using an in-solution digestion procedure according to the manufacturer's instructions (Agilent Technologies, Santa Clara, CA, USA). Briefly, $25 \mu \mathrm{L}$ of $100 \mathrm{mM}$ ammonium bicarbonate (ABC), $25 \mu \mathrm{L}$ of trifluoroethanol (TFE), and $1 \mu \mathrm{L}$ of dithiothreitol (DTT) were added to concentrated protein crude venom samples and fractions. The mixture was briefly vortexed and incubated at $60{ }^{\circ} \mathrm{C}$ for $60 \mathrm{~min}$, followed by incubation with $4 \mu \mathrm{L}$ of iodoacetamide at $37^{\circ} \mathrm{C}$ for another $60 \mathrm{~min} .1 \mu \mathrm{L}$ of DTT was added to the solution and incubated again for another $60 \mathrm{~min} .100 \mathrm{mM} \mathrm{ABC}$ and trypsin [1:50 $(w / w)$ enzyme-to-substrate ratio; approximately $500 \mathrm{ng}$ ] were then added to the solution and incubated at $37^{\circ} \mathrm{C}$ for $18 \mathrm{~h}$. At the end of the incubation, trypsin activity was terminated by adding formic acid and finally subjected to centrifugal vacuum evaporation to remove solvents and concentrate the sample simultaneously. Samples were monitored for 1 to 2 days until completely dry and subsequently stored at $-20{ }^{\circ} \mathrm{C}$ until LC-MS/MS analysis.

\subsubsection{Identification of Crude Venom Proteins Using Shotgun LCMS/MS}

Previously frozen lyophilized C. rhodostoma and O. hannah venoms were adjusted to $200 \mu \mathrm{g}$ protein samples and subjected to in-solution tryptic digest protocol as described in Section 4.2.2. The crude venom samples from three separately pooled stocks were utilized for this study.

\subsubsection{Fractionation of C. rhodostoma and O. hannah Crude Venoms by Superdex G-75 Gel} Filtration Chromatography

Freeze-dried crude venoms (10 mg) were dissolved in $0.01 \mathrm{M}$ ammonium acetate $(250 \mu \mathrm{L} ; \mathrm{pH} 7.0)$ and centrifuged at $5000 \times g$ for $1 \mathrm{~min}$ to remove insoluble material. The clarified supernatant was 
subjected to gel filtration chromatography via Superdex G-75 pre-equilibrated and eluted with the same buffer at a flow rate of $0.5 \mathrm{~mL} / \mathrm{min}$. The fractionation was monitored using a fast protein liquid chromatography system (AKTA Prime Plus, GE Healthcare, Uppsala, Sweden) and carried out at room temperature. The chromatographic data were acquired and processed using Unicorn 5.20 Workstation software (GE Healthcare, Uppsala, Sweden). All fractions were pooled and subjected to buffer exchange using a Hi-Trap G-25 desalting column. Desalted fractions were concentrated and stored at $-20{ }^{\circ} \mathrm{C}$ until required for mass spectrometry identification analysis. Samples from three separately pooled stocks were adjusted to $200 \mu \mathrm{g}$ before being subjected to in-solution tryptic digest.

\subsubsection{LC-MS/MS Analysis of Crude Venom and Gel-Filtration Protein Fractions}

Tryptic-digested peptides stored in $-20{ }^{\circ} \mathrm{C}$ were reconstituted in $20 \mu \mathrm{L}$ of $0.1 \%$ formic acid in water. $1 \mu \mathrm{L}$ of peptide sample was injected on a nano C-18 column (see below) using the Agilent 1200 capillary nanoflow liquid chromatography system coupled to a 6550 iFunnel Q-TOF LC/MS mass spectrometer (Agilent) via a nano-electrospray (Nano-ESI) source. Digested peptide products were separated using the C18 $300 \AA$ Large Capacity Chip column (Zorbax 300SB-C18) that was pre-equilibrated with $0.1 \%$ formic acid in water (A) and eluted in a multi-gradient approach using $90 \%$ acetonitrile in $0.1 \%$ formic acid in water (B) at a flow rate of $4 \mu \mathrm{L} / \mathrm{min}$. The method utilized a $47 \mathrm{~min}$ gradient starting with a 30 min ramping from $3 \%$ to $50 \%$ solution $B$, followed by a further increase of $50 \%$ to $95 \%$ solution B for $2 \mathrm{~min}$, $95 \%$ solution B for $7 \mathrm{~min}$, and finally a decrease from $95 \%$ to $3 \%$ solution B for another $8 \mathrm{~min}$. BSA was used as a standard for reference. Mass spectrometry (MS/MS) was performed using these following settings: Gas temperature $300^{\circ} \mathrm{C}$; drying gas $5 \mathrm{~L} / \mathrm{min}$; capillary voltage of $2050 \mathrm{~V}$; and fragmenter voltage $300 \mathrm{~V}$. The auto MS/MS mode was used, with positive ion polarity setup. Acquisition ranges were 110-3000 m/ $z$ for MS scan and 50-3000 m/z for MS/MS scan.

\subsubsection{Data Analysis}

Data analysis and protein identification by automated de novo sequencing was performed using PEAKS 8.0 software (Bioinformatics Solutions Inc., Waterloo, ON, Canada). MS/MS spectra were searched against the Swiss-Prot database (July 2017) by selecting all proteins from the Serpentes taxa subjected to the following parameters: Digestion Trypsin; maximum number of missed cleavages 3; fixed modification: carbamidomethylation; mass error tolerance (parent and fragment) $0.1 \mathrm{Da}$; false discovery rate (FDR) 1\%; unique peptides 2; and peptide hit threshold (-10lgP) 20. Venom components were classified according to protein families and their relative abundances were calculated according to Zainal Abidin et al. (2016) [62] as follows:

$$
\frac{\text { number of proteins (protein family) }}{\text { total proteins detected using LC }- \text { MS } / \mathrm{MS}} \times 100 \%
$$

Relative abundance was expressed as percentages and represented in pie charts. A complete list of identified peptides and proteins is included as Supplementary Material (Tables S1-S4).

Supplementary Materials: The following are available online at http://www.mdpi.com/2072-6651/10/11/ 434/s1, Table S1: Complete mass spectrophotometry data of Malaysian Calloselasma rhodostoma (Malayan pit viper) crude venom via shotgun-ESI-LC-MS/MS analysis, Table S2: Complete mass spectrophotometry data of Malaysian Ophiophagus hannah (King cobra) crude venom via shotgun-ESI-LC-MS/MS analysis, Table S3: Complete mass spectrophotometry data of Malaysian Calloselasma rhodostoma (Malayan pit viper) crude venom via GF-ESI-LC-MS/MS analysis, Table S4: Complete mass spectrophotometry data of Malaysian Ophiophagus hannah (King cobra) crude venom via GF-ESI-LC-MS/MS analysis.

Author Contributions: S.K. was responsible for the design and execution of the experiments, data analysis and writing of the manuscript. I.O. conceived the experiments and provided critical feedback. S.S.H. provided critical feedback. W.C.H. analyzed the data, wrote and provided critical feedback for the manuscript.

Funding: W.C.H. is funded by a National Health and Medical Research Council (NHMRC)—Australia, Centres for Research Excellence Grant ID: 1110343. 
Acknowledgments: The authors would like to acknowledge Jeffrey Cheah School of Medicine and Health Sciences, Monash University Malaysia for research facilities and support. We would also like to thank Nurziana Sharmilla, Tee Ting Yee and Adillah Akhasan from Jeffrey Cheah School of Medicine and Health Sciences Proteomics laboratory for assistance with operation of the LC-MS systems.

Conflicts of Interest: The authors declare no conflict of interest.

\section{References}

1. Williams, D.; Gutiérrez, J.M.; Harrison, R.; Warrell, D.A.; White, J.; Winkel, K.D.; Gopalakrishnakone, P. The global snake bite initiative: An antidote for snake bite. Lancet 2010, 375, 89-91. [CrossRef]

2. Koh, D.; Armugam, A.; Jeyaseelan, K. Snake venom components and their applications in biomedicine. Cell. Mol. Life Sci. CMLS 2006, 63, 3030-3041. [CrossRef] [PubMed]

3. Kasai, K.; Ishikawa, T.; Nakamura, T.; Miura, T. Antibacterial properties of L-amino acid oxidase: Mechanisms of action and perspectives for therapeutic applications. Appl. Microbiol. Biotechnol. 2015, 99, 7847-7857. [CrossRef] [PubMed]

4. Gomes, A.; Bhattacharjee, P.; Mishra, R.; Biswas, A.K.; Dasgupta, S.C.; Giri, B.; Debnath, A.; Gupta, S.D.; Das, T.; Gomes, A. Anticancer potential of animal venoms and toxins. Indian J. Exp. Boil. 2010, 48, 93-103.

5. Iwanaga, S.; Suzuki, T. Enzymes in snake venom. In Snake Venoms; Springer: Berlin/Heidelberg, Germany, 1979; pp. 61-158.

6. Chellapandi, P. Structural, functional and therapeutic aspects of snake venom metalloproteinases. Mini-Rev. Org. Chem. 2014, 11, 28-44. [CrossRef]

7. King, G.F. Venoms as a platform for human drugs: Translating toxins into therapeutics. Expert Opin. Boil. Ther. 2011, 11, 1469-1484. [CrossRef] [PubMed]

8. Oldrati, V.; Arrell, M.; Violette, A.; Perret, F.; Sprüngli, X.; Wolfender, J.-L.; Stöcklin, R. Advances in venomics. Mol. Biosyst. 2016, 12, 3530-3543. [CrossRef] [PubMed]

9. Calvete, J.J. Snake venomics: From the inventory of toxins to biology. Toxicon 2013, 75, 44-62. [CrossRef] [PubMed]

10. De Lima, D.C.; Alvarez Abreu, P.; de Freitas, C.C.; Santos, D.O.; Borges, R.O.; Dos Santos, T.C.; Mendes Cabral, L.; Rodrigues, C.R.; Castro, H.C. Snake venom: Any clue for antibiotics and CAM? Evid.-Based Complement. Altern. Med. 2005, 2, 39-47. [CrossRef] [PubMed]

11. Das, I.; Ahmed, N.; Liat, L.B. Venomous terrestrial snakes of Malaysia: Their identity and biology. In Clinical Toxinology in Asia Pacific and Africa; Gopalakrishnakone, P., Faiz, M.A., Fernando, R., Gnanathasan, C.A., Habib, A.G., Yang, C.C., Eds.; Springer: Dordrecht, The Netherlands, 2015.

12. Nolan, C.; Hall, L.; Barlow, G. [17] Ancrod, the coagulating enzyme from Malayan pit viper (Agkistrodon rhodostoma) venom. Methods Enzymol. 1976, 45, 205-213. [PubMed]

13. Marsh, N.; Williams, V. Practical applications of snake venom toxins in haemostasis. Toxicon 2005, 45, 1171-1181. [CrossRef] [PubMed]

14. McCleary, R.J.; Kang, T.S.; Kini, R.M. Reptile venoms as a platform for drug development. In Venoms to Drugs: Venom as a Source for the Development of Human Therapeutics, Chapter: Reptile Venoms as a Platform for Drug Development; Royal Society of Chemistry: Cambridge, UK, 2015; pp. 129-162.

15. Slagboom, J.; Kool, J.; Harrison, R.A.; Casewell, N.R. Haemotoxic snake venoms: Their functional activity, impact on snakebite victims and pharmaceutical promise. Br. J. Haematol. 2017, 177, 947-959. [CrossRef] [PubMed]

16. $\mathrm{Pu}, \mathrm{X}$.; Wong, P.; Gopalakrishnakone, P. A novel analgesic toxin (hannalgesin) from the venom of king cobra (Ophiophagus hannah). Toxicon 1995, 33, 1425-1431. [CrossRef]

17. Koh, C.Y.; Kini, R.M. From snake venom toxins to therapeutics-cardiovascular examples. Toxicon 2012, 59, 497-506. [CrossRef] [PubMed]

18. Harvey, A.L. Toxins and drug discovery. Toxicon 2014, 92, 193-200. [CrossRef] [PubMed]

19. Tang, E.L.; Tan, C.H.; Fung, S.Y.; Tan, N.H. Venomics of Calloselasma rhodostoma, the Malayan pit viper: A complex toxin arsenal unraveled. J. Proteom. 2016, 148, 44-56. [CrossRef] [PubMed]

20. Ali, S.A.; Baumann, K.; Jackson, T.N.; Wood, K.; Mason, S.; Undheim, E.A.; Nouwens, A.; Koludarov, I.; Hendrikx, I.; Jones, A.; et al. Proteomic comparison of Hypnale hypnale (Hump-Nosed Pit-Viper) and Calloselasma rhodostoma (Malayan Pit-Viper) venoms. J. Proteom. 2013, 91, 338-343. [CrossRef] [PubMed] 
21. Vejayan, J.; Khoon, T.L.; Ibrahim, H. Comparative analysis of the venom proteome of four important Malaysian snake species. J. Venom. Anim. Toxins Incl. Trop. Dis. 2014, 20, 6. [CrossRef] [PubMed]

22. Tan, C.H.; Tan, K.Y.; Fung, S.Y.; Tan, N.H. Venom-gland transcriptome and venom proteome of the Malaysian king cobra (Ophiophagus hannah). BMC Genom. 2015, 16, 687. [CrossRef] [PubMed]

23. Vonk, F.J.; Casewell, N.R.; Henkel, C.V.; Heimberg, A.M.; Jansen, H.J.; McCleary, R.J.; Kerkkamp, H.M.; Vos, R.A.; Guerreiro, I.; Calvete, J.J.; et al. The king cobra genome reveals dynamic gene evolution and adaptation in the snake venom system. Proc. Natl. Acad. Sci. USA 2013, 110, 20651-20656. [CrossRef] [PubMed]

24. Khow, O.; Chulasugandha, P.; Pakmanee, N. Venom protein of the haematotoxic snakes Cryptelytrops albolabris, Calloselasma rhodostoma, and Daboia russelii siamensis. Sci. Asia 2011, 37, 377-381. [CrossRef]

25. Choudhury, M.; McCleary, R.J.; Kesherwani, M.; Kini, R.M.; Velmurugan, D. Comparison of proteomic profiles of the venoms of two of the 'Big Four' snakes of India, the Indian cobra (Naja naja) and the common krait (Bungarus caeruleus), and analyses of their toxins. Toxicon 2017, 135, 33-42. [CrossRef] [PubMed]

26. Shuting, L.; Jingqiang, W.; Zhang, X.; Yan, R.; Ning, W.; Kang, Z.; Xishu, C.; Caifeng, Z.; Xiaolei, L.; Jianmin, S.; et al. Proteomic characterization of two snake venoms: Naja naja atra and Agkistrodon halys. Biochem. J. 2004, 384, 119-127.

27. De Oliveira, I.S.; Cardoso, I.A.; Bordon, K.D.C.F.; Carone, S.E.I.; Boldrini-França, J.; Pucca, M.B.; Zoccal, K.F.; Faccioli, L.H.; Sampaio, S.V.; Rosa, J.C.; et al. Global proteomic and functional analysis of Crotalus durissus collilineatus individual venom variation and its impact on envenoming. J. Proteom. 2018, 2018. [CrossRef] [PubMed]

28. Vaiyapuri, S.; Wagstaff, S.C.; Watson, K.A.; Harrison, R.A.; Gibbins, J.M.; Hutchinson, E.G. Purification and functional characterisation of rhiminopeptidase A, a novel aminopeptidase from the venom of Bitis gabonica rhinoceros. PLoS Negl. Trop. Dis. 2010, 4, e796. [CrossRef] [PubMed]

29. Markland, F.S., Jr.; Swenson, S. Snake venom metalloproteinases. Toxicon 2013, 62, 3-18. [CrossRef] [PubMed]

30. Fox, J.W.; Serrano, S.M. Timeline of key events in snake venom metalloproteinase research. J. Proteom. 2009, 72, 200-209. [CrossRef] [PubMed]

31. Fox, J.W.; Serrano, S.M. Structural considerations of the snake venom metalloproteinases, key members of the M12 reprolysin family of metalloproteinases. Toxicon 2005, 45, 969-985. [CrossRef] [PubMed]

32. Tasoulis, T.; Isbister, G.K. A review and database of snake venom proteomes. Toxins 2017, 9, 290. [CrossRef] [PubMed]

33. Serrano, S.M. The long road of research on snake venom serine proteinases. Toxicon 2013, 62, 19-26. [CrossRef] [PubMed]

34. Serrano, S.M.; Maroun, R.C. Snake venom serine proteinases: Sequence homology vs. Substrate specificity, a paradox to be solved. Toxicon 2005, 45, 1115-1132. [CrossRef] [PubMed]

35. Stubbs, M.T.; Bode, W. A player of many parts: The spotlight falls on thrombin's structure. Thromb. Res. 1993, 69, 1-58. [CrossRef]

36. Esnouf, M.; Tunnah, G. The isolation and properties of the thrombin-like activity from Ancistrodon rhodostoma venom. Br. J. Haematol. 1967, 13, 581-590. [CrossRef] [PubMed]

37. Sanggaard, K.W.; Dyrlund, T.F.; Thomsen, L.R.; Nielsen, T.A.; Brøndum, L.; Wang, T.; Thøgersen, I.B.; Enghild, J.J. Characterization of the gila monster (Heloderma suspectum suspectum) venom proteome. J. Proteom. 2015, 117, 1-11. [CrossRef] [PubMed]

38. Sanggaard, K.W.; Bechsgaard, J.S.; Fang, X.; Duan, J.; Dyrlund, T.F.; Gupta, V.; Jiang, X.; Cheng, L.; Fan, D.; Feng, Y.; et al. Spider genomes provide insight into composition and evolution of venom and silk. Nat. Commun. 2014, 5, 3765. [CrossRef] [PubMed]

39. Safavi-Hemami, H.; Hu, H.; Gorasia, D.G.; Bandyopadhyay, P.K.; Veith, P.D.; Young, N.D.; Reynolds, E.C.; Yandell, M.; Olivera, B.M.; Purcell, A.W. Combined proteomic and transcriptomic interrogation of the venom gland of Conus geographus uncovers novel components and functional compartmentalization. Mol. Cell. Proteom. 2014, 13, 938-953. [CrossRef] [PubMed]

40. Robinson, S.D.; Safavi-Hemami, H.; McIntosh, L.D.; Purcell, A.W.; Norton, R.S.; Papenfuss, A.T. Diversity of conotoxin gene superfamilies in the venomous snail, Conus victoriae. PLoS ONE 2014, 9, e87648. [CrossRef] [PubMed] 
41. Hook, V.; Yasothornsrikul, S.; Greenbaum, D.; Medzihradszky, K.F.; Troutner, K.; Toneff, T.; Bundey, R.; Logrinova, A.; Reinheckel, T.; Peters, C.; et al. Cathepsin L and Arg/Lys aminopeptidase: A distinct prohormone processing pathway for the biosynthesis of peptide neurotransmitters and hormones. Boil. Chem. 2004, 385, 473-480. [CrossRef] [PubMed]

42. Jackson, R.S.; Creemers, J.W.; Ohagi, S.; Raffin-Sanson, M.-L.; Sanders, L.; Montague, C.T.; Hutton, J.C.; O'Rahilly, S. Obesity and impaired prohormone processing associated with mutations in the human prohormone convertase 1 gene. Nat. Genet. 1997, 16, 303. [CrossRef] [PubMed]

43. Milne, T.J.; Abbenante, G.; Tyndall, J.D.; Halliday, J.; Lewis, R.J. Isolation and characterization of a cone snail protease with homology to crisp proteins of the pathogenesis-related protein superfamily. J. Boil. Chem. 2003, 278, 31105-31110. [CrossRef] [PubMed]

44. Yamazaki, Y.; Morita, T. Structure and function of snake venom cysteine-rich secretory proteins. Toxicon 2004, 44, 227-231. [CrossRef] [PubMed]

45. Yamazaki, Y.; Morita, T. Snake venom components affecting blood coagulation and the vascular system: Structural similarities and marked diversity. Curr. Pharm. Des. 2007, 13, 2872-2886. [CrossRef] [PubMed]

46. Sunagar, K.; Johnson, W.E.; O’Brien, S.J.; Vasconcelos, V.; Antunes, A. Evolution of crisps associated with toxicoferan-reptilian venom and mammalian reproduction. Mol. Boil. Evol. 2012, 29, 1807-1822. [CrossRef] [PubMed]

47. Matsunaga, Y.; Yamazaki, Y.; Hyodo, F.; Sugiyama, Y.; Nozaki, M.; Morita, T. Structural divergence of cysteine-rich secretory proteins in snake venoms. J. Biochem. 2008, 145, 365-375. [CrossRef] [PubMed]

48. Brown, R.L.; Haley, T.L.; West, K.A.; Crabb, J.W. Pseudechetoxin: A peptide blocker of cyclic nucleotide-gated ion channels. Proc. Natl. Acad. Sci. USA 1999, 96, 754-759. [CrossRef] [PubMed]

49. Yamazaki, Y.; Hyodo, F.; Morita, T. Wide distribution of cysteine-rich secretory proteins in snake venoms: Isolation and cloning of novel snake venom cysteine-rich secretory proteins. Arch. Biochem. Biophys. 2003, 412, 133-141. [CrossRef]

50. Kini, R.M. Excitement ahead: Structure, function and mechanism of snake venom phospholipase $\mathrm{A}_{2}$ enzymes. Toxicon 2003, 42, 827-840. [CrossRef] [PubMed]

51. Gutiérrez, J.M.; Lomonte, B. Phospholipases $\mathrm{A}_{2}$ : Unveiling the secrets of a functionally versatile group of snake venom toxins. Toxicon 2013, 62, 27-39. [CrossRef] [PubMed]

52. Tsai, I.H.; Wang, Y.M.; Au, L.C.; Ko, T.P.; Chen, Y.H.; Chu, Y.F. Phospholipases $\mathrm{A}_{2}$ from Callosellasma rhodostoma venom gland. FEBS J. 2000, 267, 6684-6691. [CrossRef]

53. Tsai, S.-H.; Chen, Y.-C.; Chen, L.; Wang, Y.-M.; Tsai, I.-H. Binding of a venom Lys-49 phospholipase $\mathrm{A}_{2}$ to LPS and suppression of its effects on mouse macrophages. Toxicon 2007, 50, 914-922. [CrossRef] [PubMed]

54. Tan, N.H.; Fung, S.Y.; Tan, K.Y.; Yap, M.K.K.; Gnanathasan, C.A.; Tan, C.H. Functional venomics of the Sri Lankan Russell's viper (Daboia russelii) and its toxinological correlations. J. Proteom. 2015, 128, 403-423. [CrossRef] [PubMed]

55. Doery, H.M.; Pearson, J.E. Phospholipase B in snake venoms and bee venom. Biochem. J. 1964, $92,599$. [CrossRef] [PubMed]

56. Van Deenen, L.L.M.; de Haas, G.H. The substrate specificity of phospholipase A. Biochim. Biophys. Acta (BBA) Spéc. Sect. Lipids Relat. Subj. 1963, 70, 538-553.

57. Mohamed, A.; Kamel, A.; Ayobe, M. Studies of phospholipase A and B activities of Egyptian snake venoms and a scorpion toxin. Toxicon 1969, 6, 293-298. [CrossRef]

58. Shiloah, J.; Klibansky, C.; De Vries, A.; Berger, A. Phospholipase B activity of a purified phospholipase A from Vipera palestinae venom. J. Lipid Res. 1973, 14, 267-278. [PubMed]

59. Bernheimer, A.; Linder, R.; Weinstein, S.; Kim, K.-S. Isolation and characterization of a phospholipase B from venom of collett's snake, Pseudechis colletti. Toxicon 1987, 25, 547-554. [CrossRef]

60. Kovalchuk, S.I.; Ziganshin, R.H.; Starkov, V.G.; Tsetlin, V.I.; Utkin, Y.N. Quantitative proteomic analysis of venoms from Russian vipers of Pelias group: Phospholipases $\mathrm{A}_{2}$ are the main venom components. Toxins 2016, 8, 105. [CrossRef] [PubMed]

61. Ziganshin, R.H.; Kovalchuk, S.I.; Arapidi, G.P.; Starkov, V.G.; Hoang, A.N.; Nguyen, T.T.T.; Nguyen, K.C.; Shoibonov, B.B.; Tsetlin, V.I.; Utkin, Y.N. Quantitative proteomic analysis of Vietnamese krait venoms: Neurotoxins are the major components in Bungarus multicinctus and phospholipases $\mathrm{A}_{2}$ in Bungarus fasciatus. Toxicon 2015, 107, 197-209. [CrossRef] [PubMed] 
62. Zainal Abidin, S.A.; Rajadurai, P.; Chowdhury, M.E.H.; Ahmad Rusmili, M.R.; Othman, I.; Naidu, R. Proteomic characterization and comparison of malaysian Tropidolaemus wagleri and Cryptelytrops purpureomaculatus venom using shotgun-proteomics. Toxins 2016, 8, 299. [CrossRef] [PubMed]

63. Morita, T. Structures and functions of snake venom CLPs (C-type lectin-like proteins) with anticoagulant-, procoagulant-, and platelet-modulating activities. Toxicon 2005, 45, 1099-1114. [CrossRef] [PubMed]

64. Clemetson, K.J. Snaclecs (snake C-type lectins) that inhibit or activate platelets by binding to receptors. Toxicon 2010, 56, 1236-1246. [CrossRef] [PubMed]

65. Qinghua, L.; Xiaowei, Z.; Wei, Y.; Chenji, L.; Yijun, H.; Pengxin, Q.; Xingwen, S.; Songnian, H.; Guangmei, Y. A catalog for transcripts in the venom gland of the Agkistrodon acutus: Identification of the toxins potentially involved in coagulopathy. Biochem. Biophys. Res. Commun. 2006, 341, 522-531. [CrossRef] [PubMed]

66. Tan, C.H.; Tan, N.H.; Sim, S.M.; Fung, S.Y.; Gnanathasan, C.A. Proteomic investigation of Sri Lankan hump-nosed pit viper (Hypnale hypnale) venom. Toxicon 2015, 93, 164-170. [CrossRef] [PubMed]

67. Du, X.-Y.; Clemetson, K.J. Snake venom L-amino acid oxidases. Toxicon 2002, 40, 659-665. [CrossRef]

68. Fung, S.; Tan, N. Snake venom L-amino acid oxidases. In Handbook of Venoms and Toxins of Reptiles; CRC Press Inc.: London, UK, 2009; pp. 221-235.

69. Baby, J.; Rajan Sheeja, S.; Jeevitha, M.; Ajisha, S. Pharmacological effects of snake venom L-amino acid oxidases. Int. J. Res. Ayurveda Pharm. 2011, 2, 114-120.

70. Fry, B. Venomous Reptiles and Their Toxins: Evolution, Pathophysiology and Biodiscovery; Oxford University Press: Oxford, UK, 2015.

71. Ponnudurai, G.; Chung, M.C.; Tan, N.-H. Purification and properties of the L-amino acid oxidase from Malayan pit viper (Calloselasma rhodostoma) venom. Arch. Biochem. Biophys. 1994, 313, 373-378. [CrossRef] [PubMed]

72. Cohen, S.; Levi-Montalcini, R. A nerve growth-stimulating factor isolated from snake venom. Proc. Natl. Acad. Sci. USA 1956, 42, 571-574. [CrossRef] [PubMed]

73. McCleary, R.J.; Kini, R.M. Non-enzymatic proteins from snake venoms: A gold mine of pharmacological tools and drug leads. Toxicon 2013, 62, 56-74. [CrossRef] [PubMed]

74. Trummal, K.; Tõnismägi, K.; Paalme, V.; Järvekülg, L.; Siigur, J.; Siigur, E. Molecular diversity of snake venom nerve growth factors. Toxicon 2011, 58, 363-368. [CrossRef] [PubMed]

75. Earl, S.T.; Birrell, G.W.; Wallis, T.P.; St Pierre, L.D.; Masci, P.P.; de Jersey, J.; Gorman, J.J.; Lavin, M.F. Post-translational modification accounts for the presence of varied forms of nerve growth factor in Australian elapid snake venoms. Proteomics 2006, 6, 6554-6565. [CrossRef] [PubMed]

76. Kostiza, T.; Meier, J. Nerve growth factors from snake venoms: Chemical properties, mode of action and biological significance. Toxicon 1996, 34, 787-806. [CrossRef]

77. Boldrini-França, J.; Cologna, C.T.; Pucca, M.B.; Bordon, K.D.C.F.; Amorim, F.G.; Anjolette, F.A.P.; Cordeiro, F.A.; Wiezel, G.A.; Cerni, F.A.; Pinheiro-Junior, E.L.; et al. Minor snake venom proteins: Structure, function and potential applications. Biochim. Biophys. Acta (BBA) Gen. Subj. 2017, 1861, 824-838. [CrossRef] [PubMed]

78. Aird, S.D. Ophidian envenomation strategies and the role of purines. Toxicon 2002, 40, 335-393. [CrossRef]

79. Dhananjaya, B.L.; D'souza, C.J. The pharmacological role of nucleotidases in snake venoms. Cell Biochem. Funct. 2010, 28, 171-177. [CrossRef] [PubMed]

80. Danpaiboon, W.; Reamtong, O.; Sookrung, N.; Seesuay, W.; Sakolvaree, Y.; Thanongsaksrikul, J.; Dong-din-on, F.; Srimanote, P.; Thueng-in, K.; Chaicumpa, W. Ophiophagus hannah venom: Proteome, components bound by Naja kaouthia antivenin and neutralization by N. kaouthia neurotoxin-specific human ScFv. Toxins 2014, 6, 1526-1558. [CrossRef] [PubMed]

81. Dhananjaya, B.; D'souza, C.J. An overview on nucleases (DNase, RNase, and phosphodiesterase) in snake venoms. Biochemistry. 2010, 75, 1-6. [CrossRef] [PubMed]

82. Aird, S.D. Taxonomic distribution and quantitative analysis of free purine and pyrimidine nucleosides in snake venoms. Comp. Biochem. Physiol. Part B Biochem. Mol. Boil. 2005, 140, 109-126. [CrossRef] [PubMed]

83. Ouyang, C.; Huang, T.-F. Inhibition of platelet aggregation by $5^{\prime}$-nucleotidase purified from Trimeresurus gramineus snake venom. Toxicon 1983, 21, 491-501. [CrossRef]

84. Ouyang, C.; Huang, T.-F. Platelet aggregation inhibitors from Agkistrodon acutus snake venom. Toxicon 1986, 24, 1099-1106. [CrossRef] 
85. Boffa, M.-C.; Boffa, G.A. Correlations between the enzymatic activities and the factors active on blood coagulation and platelet aggregation from the venom of Vipera aspis. Biochim. Biophys. Acta (BBA) Gen. Subj. 1974, 354, 275-290. [CrossRef]

86. Dhananjaya, B.; Nataraju, A.; Rajesh, R.; Gowda, C.R.; Sharath, B.; Vishwanath, B.; D'Souza, C.J. Anticoagulant effect of Naja naja venom $5^{\prime}$ nucleotidase: Demonstration through the use of novel specific inhibitor, vanillic acid. Toxicon 2006, 48, 411-421. [CrossRef] [PubMed]

87. Yap, M.K.; Fung, S.Y.; Tan, K.Y.; Tan, N.H. Proteomic characterization of venom of the medically important Southeast Asian Naja sumatrana (Equatorial spitting cobra). Acta Trop. 2014, 133, 15-25. [CrossRef] [PubMed]

88. Melani, R.D.; Araujo, G.D.; Carvalho, P.C.; Goto, L.; Nogueira, F.C.; Junqueira, M.; Domont, G.B. Seeing beyond the tip of the iceberg: A deep analysis of the venome of the Brazilian Rattlesnake, Crotalus durissus terrificus. EuPA Open Proteom. 2015, 8, 144-156. [CrossRef]

89. Aird, S.D.; Watanabe, Y.; Villar-Briones, A.; Roy, M.C.; Terada, K.; Mikheyev, A.S. Quantitative high-throughput profiling of snake venom gland transcriptomes and proteomes (Ovophis okinavensis and Protobothrops flavoviridis). BMC Genom. 2013, 14, 790. [CrossRef] [PubMed]

90. Georgieva, D.; Öhler, M.; Seifert, J.; Von Bergen, M.; Arni, R.K.; Genov, N.; Betzel, C. Snake venomic of Crotalus durissus terrificus-Correlation with pharmacological activities. J. Proteome Res. 2010, 9, 2302-2316. [CrossRef] [PubMed]

91. Fox, J.W.; Ma, L.; Nelson, K.; Sherman, N.E.; Serrano, S.M. Comparison of indirect and direct approaches using ion-trap and Fourier transform ion cyclotron resonance mass spectrometry for exploring viperid venom proteomes. Toxicon 2006, 47, 700-714. [CrossRef] [PubMed]

92. Chapeaurouge, A.; Reza, M.A.; Mackessy, S.P.; Carvalho, P.C.; Valente, R.H.; Teixeira-Ferreira, A.; Perales, J.; Lin, Q.; Kini, R.M. Interrogating the venom of the viperid snake Sistrurus catenatus edwardsii by a combined approach of electrospray and MALDI mass spectrometry. PLoS ONE 2015, 10, e0092091. [CrossRef] [PubMed]

93. Gonçalves-Machado, L.; Pla, D.; Sanz, L.; Jorge, R.J.B.; Leitão-De-Araújo, M.; Alves, M.L.M.; Alvares, D.J.; De Miranda, J.; Nowatzki, J.; de Morais-Zani, K.; et al. Combined venomics, venom gland transcriptomics, bioactivities, and antivenomics of two Bothrops jararaca populations from geographic isolated regions within the Brazilian Atlantic rainforest. J. Proteom. 2016, 135, 73-89. [CrossRef] [PubMed]

94. Wang, Y.-M.; Huang, K.-F.; Tsai, I.-H. Snake venom glutaminyl cyclases: Purification, cloning, kinetic study, recombinant expression, and comparison with the human enzyme. Toxicon 2014, 86, 40-50. [CrossRef] [PubMed]

95. Pawlak, J.; Kini, R.M. Snake venom glutaminyl cyclase. Toxicon 2006, 48, 278-286. [CrossRef] [PubMed]

96. Breeden, L.; Nasmyth, K. Similarity between cell-cycle genes of budding yeast and fission yeast and the Notch gene of Drosophila. Nature 1987, 329, 651-654. [CrossRef] [PubMed]

97. Foord, R.; Taylor, I.A.; Sedgwick, S.G.; Smerdon, S.J. X-ray structural analysis of the yeast cell cycle regulator Swi6 reveals variations of the ankyrin fold and has implications for Swi6 function. Nat. Struct. Mol. Boil. 1999, 6, 157-165.

98. He, Q.; Duan, Z.; Yu, Y.; Liu, Z.; Liu, Z.; Liang, S. The venom gland transcriptome of Latrodectus tredecimguttatus revealed by deep sequencing and cDNA library analysis. PLoS ONE 2013, 8, e81357. [CrossRef] [PubMed]

99. Kini, R.M. Molecular moulds with multiple missions: Functional sites in three-finger toxins. Clin. Exp. Pharmacol. Physiol. 2002, 29, 815-822. [CrossRef] [PubMed]

100. Kini, R.M.; Doley, R. Structure, function and evolution of three-finger toxins: Mini proteins with multiple targets. Toxicon 2010, 56, 855-867. [CrossRef] [PubMed]

101. Dufton, M.; Hider, R. Structure and pharmacology of elapid cytotoxins. Pharmacol. Ther. 1988, 36, 1-40. [CrossRef]

102. Fry, B.G.; Lumsden, N.G.; Wüster, W.; Wickramaratna, J.C.; Hodgson, W.C.; Kini, R.M. Isolation of a neurotoxin ( $\alpha$-colubritoxin) from a nonvenomous colubrid: Evidence for early origin of venom in snakes. J. Mol. Evol. 2003, 57, 446-452. [CrossRef] [PubMed]

103. Vogel, C.-W.; Bredehorst, R.; Fritzinger, D.C.; Grunwald, T.; Ziegelmüller, P.; Kock, M.A. Structure and function of cobra venom factor, the complement-activating protein in cobra venom. In Natural Toxins 2; Springer: Boston, MA, USA, 1996; pp. 97-114.

104. Vogel, C.-W.; Fritzinger, D.C. Cobra venom factor: Structure, function, and humanization for therapeutic complement depletion. Toxicon 2010, 56, 1198-1222. [CrossRef] [PubMed] 
105. Ranasinghe, S.; McManus, D.P. Structure and function of invertebrate Kunitz serine protease inhibitors. Dev. Comp. Immunol. 2013, 39, 219-227. [CrossRef] [PubMed]

106. Župunski, V.; Kordiš, D.; Gubenšek, F. Adaptive evolution in the snake venom Kunitz/BPTI protein family. FEBS Lett. 2003, 547, 131-136. [CrossRef]

107. Yang, W.; Feng, J.; Wang, B.; Cao, Z.; Li, W.; Wu, Y.; Chen, Z. BF9, the first functionally characterized snake toxin peptide with Kunitz-type protease and potassium channel inhibiting properties. J. Biochem. Mol. Toxicol. 2014, 28, 76-83. [CrossRef] [PubMed]

108. Shafqat, J.; Beg, O.U.; Yin, S.J.; Zaidi, Z.H.; Jörnvall, H. Primary structure and functional properties of cobra (Naja naja naja) venom Kunitz-type trypsin inhibitor. FEBS J. 1990, 194, 337-341. [CrossRef]

109. Shabanpoor, F.; Separovic, F.; Wade, J.D. The human insulin superfamily of polypeptide hormones. Vitam. Horm. 2009, 80, 1-31. [PubMed]

110. Safavi-Hemami, H.; Gajewiak, J.; Karanth, S.; Robinson, S.D.; Ueberheide, B.; Douglass, A.D.; Schlegel, A.; Imperial, J.S.; Watkins, M.; Bandyopadhyay, P.K.; et al. Specialized insulin is used for chemical warfare by fish-hunting cone snails. Proc. Natl. Acad. Sci. USA 2015, 112, 1743-1748. [CrossRef] [PubMed]

111. Iyengar, N.; Sehra, K.; Mukerji, B.; Chopra, R. Choline esterase in cobra venom. Curr. Sci. 1938, 7, 51-53.

112. Frobert, Y.; Créminon, C.; Cousin, X.; Rémy, M.-H.; Chatel, J.-M.; Bon, S.; Bon, C.; Grassi, J. Acetylcholinesterases from Elapidae snake venoms: Biochemical, immunological and enzymatic characterization. Biochim. Biophys. Acta (BBA) Protein Struct. Mol. Enzym. 1997, 1339, 253-267. [CrossRef]

113. Kerr, M.; Kenny, A. The purification and specificity of a neutral endopeptidase from rabbit kidney brush border. Biochem. J. 1974, 137, 477-488. [CrossRef] [PubMed]

114. Casewell, N.R.; Harrison, R.A.; Wüster, W.; Wagstaff, S.C. Comparative venom gland transcriptome surveys of the saw-scaled vipers (Viperidae: Echis) reveal substantial intra-family gene diversity and novel venom transcripts. BMC Genom. 2009, 10, 564. [CrossRef] [PubMed]

115. Turner, A.J.; Isaac, R.E.; Coates, D. The neprilysin (NEP) family of zinc metalloendopeptidases: Genomics and function. Bioessays 2001, 23, 261-269. [CrossRef]

116. Pung, Y.F.; Wong, P.T.; Kumar, P.P.; Hodgson, W.C.; Kini, R.M. Ohanin, a novel protein from king cobra venom, induces hypolocomotion and hyperalgesia in mice. J. Boil. Chem. 2005, 280, 13137-13147. [CrossRef] [PubMed]

117. Pung, Y.F.; Kumar, S.V.; Rajagopalan, N.; Fry, B.G.; Kumar, P.P.; Kini, R.M. Ohanin, a novel protein from king cobra venom: Its cDNA and genomic organization. Gene 2006, 371, 246-256. [CrossRef] [PubMed]

118. Gopalakrishnakone, P.; Pu, X.C.; Wong, P.T.-H.; Gwee, M.C.E.; Kini, R.M. Therapeutic Molecules Derived from Snake Venom. U.S. Patent 6613745B1, 2 September 2003.

119. Wordinger, R.J.; Clark, A.F. Growth factors and neurotrophic factors as targets. Ocul. Ther. 2008, 87-116. [CrossRef]

120. Mori, T.; Shimizu, A.; Masuda, Y.; Fukuda, Y.; Yamanaka, N. Hepatocyte growth factor-stimulating endothelial cell growth and accelerating glomerular capillary repair in experimental progressive glomerulonephritis. Nephron Exp. Nephrol. 2003, 94, e44-e54. [CrossRef] [PubMed]

121. Laemmli, J. SDS-polyacrylamide gel electrophoresis of protein. Nature 1970, 2, 680-685. [CrossRef]

(C) 2018 by the authors. Licensee MDPI, Basel, Switzerland. This article is an open access article distributed under the terms and conditions of the Creative Commons Attribution (CC BY) license (http:// creativecommons.org/licenses/by/4.0/). 